\title{
Generating global Leaf Area Index from Landsat: Algorithm formulation and demonstration
}

\author{
Sangram Ganguly ${ }^{\mathrm{a}, *}$, Ramakrishna R. Nemani ${ }^{\mathrm{b}}$, Gong Zhang ${ }^{\mathrm{c}}$, Hirofumi Hashimoto ${ }^{\mathrm{d}}$, Cristina Milesi ${ }^{\mathrm{d}}$, \\ Andrew Michaelis ${ }^{d}$, Weile Wang ${ }^{d}$, Petr Votava ${ }^{d}$, Arindam Samanta ${ }^{\text {e }}$, Forrest Melton ${ }^{d}$, Jennifer L. Dungan ${ }^{b}$, \\ Eric Vermote ${ }^{\mathrm{f}}$, Feng Gao ${ }^{\mathrm{g}}$, Yuri Knyazikhin ${ }^{\mathrm{h}}$, Ranga B. Myneni ${ }^{\mathrm{h}}$ \\ a Bay Area Environmental Research Institute (BAERI)/NASA Ames Research Center, Moffett Field, CA 94035, USA \\ ${ }^{\mathrm{b}}$ Biospheric Science Branch, NASA Ames Research Center, Moffett Field, CA 94035, USA \\ c Department of Watershed Science, Utah State University, UT 84322, USA \\ d Department of Science and Environmental Policy, California State University at Monterey Bay/NASA Ames Research Center, Moffett Field, CA 94035, USA \\ e Atmospheric and Environmental Research (AER) Inc., Lexington, MA 02421, USA \\ f Department of Geography, University of Maryland, College Park, MD 20771, USA \\ giospheric Sciences Branch, NASA Goddard Space Flight Center, Greenbelt, MD 20771, USA \\ ${ }^{\mathrm{h}}$ Department of Geography and Environment, Boston University, MA 02215, USA
}

\section{A R T I C L E I N F O}

\section{Article history:}

Received 16 March 2011

Received in revised form 19 October 2011

Accepted 22 October 2011

Available online 10 February 2012

\section{Keywords:}

Leaf Area Index (LAI)

Landsat

Global Land Survey (GLS)

Canopy spectral invariants

\begin{abstract}
A B S T R A C T
This paper summarizes the implementation of a physically based algorithm for the retrieval of vegetation green Leaf Area Index (LAI) from Landsat surface reflectance data. The algorithm is based on the canopy spectral invariants theory and provides a computationally efficient way of parameterizing the Bidirectional Reflectance Factor (BRF) as a function of spatial resolution and wavelength. LAI retrievals from the application of this algorithm to aggregated Landsat surface reflectances are consistent with those of MODIS for homogeneous sites represented by different herbaceous and forest cover types. Example results illustrating the physics and performance of the algorithm suggest three key factors that influence the LAI retrieval process: 1) the atmospheric correction procedures to estimate surface reflectances; 2) the proximity of Landsatobserved surface reflectance and corresponding reflectances as characterized by the model simulation; and 3 ) the quality of the input land cover type in accurately delineating pure vegetated components as opposed to mixed pixels. Accounting for these factors, a pilot implementation of the LAI retrieval algorithm was demonstrated for the state of California utilizing the Global Land Survey (GLS) 2005 Landsat data archive. In a separate exercise, the performance of the LAI algorithm over California was evaluated by using the short-wave infrared band in addition to the red and near-infrared bands. Results show that the algorithm, while ingesting the short-wave infrared band, has the ability to delineate open canopies with understory effects and may provide useful information compared to a more traditional two-band retrieval. Future research will involve implementation of this algorithm at continental scales and a validation exercise will be performed in evaluating the accuracy of the 30 -m LAI products at several field sites.
\end{abstract}

(c) 2012 Elsevier Inc. All rights reserved.

\section{Introduction}

Leaf Area Index (LAI), the area of leaves per unit ground area, is an important variable for quantifying the cycling of water, carbon and nutrients through ecosystems (Demarty et al., 2007; Sellers et al., 1996; Tian, 2004). The LAI products from the Advanced Very High Resolution Radiometer (AVHRR) and the Moderate Resolution Imaging Spectroradiometer (MODIS) sensors have a large user base in the Earth science community and the ease of access, provision of pixel quality and validation information have greatly aided the use of these products. Recent

\footnotetext{
* Corresponding author at: Bay Area Environmental Research Institute/NASA Ames Research Center, MS 242-4, Moffett Field, CA 94035, USA.

E-mail address: sangramganguly@gmail.com (S. Ganguly).
}

research efforts have addressed the problem of inter-sensor product consistencies and have developed a foundation upon which existing mature algorithms and a validation framework can act synergistically to further refine the accuracy and precision of these long-term products (Brown et al., 2006; Ganguly et al., 2008a; Tarnavsky et al., 2008; Van Leeuwen et al., 2006). Multi-decadal, validated, consistent global and regional data sets of LAI from the AVHRR, MODIS, and the SPOT-VGT sensors are now available at resolutions of $1 \mathrm{~km}$ to $1^{\circ}$ in service of several national and international initiatives (Chen et al., 2002; Fernandes \& Butson, 2003; Ganguly et al., 2008b; Myneni et al., 1997). However, because of their coarse spatial resolution, these datasets preclude the modeling of ecosystem processes at regional to local levels.

Estimation of LAI from Landsat provides a unique opportunity to characterize terrestrial ecosystem processes at a high spatial resolution 
Table 1

Landsat scenes and corresponding MODIS tiles used for the biome-analysis.

\begin{tabular}{|c|c|c|c|c|c|c|c|c|c|}
\hline \multicolumn{2}{|c|}{ Landsat tile } & \multirow[t]{2}{*}{ MODIS tile } & \multirow[t]{2}{*}{ Biome type } & \multicolumn{3}{|c|}{ GLS acquisition date } & \multicolumn{3}{|c|}{ MODIS 8-day date } \\
\hline Path & Row & & & Month & Day & Year & Month & Day & Year \\
\hline 028 & 033 & h10v05 & Grasses and cereal crops & 07 & 23 & 2005 & 07 & 20 & 2005 \\
\hline 035 & 038 & h08v05 & Shrubs & 10 & 12 & 2005 & 10 & 08 & 2005 \\
\hline 023 & 032 & h11v04 & Broadleaf crops & 07 & 31 & 2006 & 07 & 28 & 2006 \\
\hline 175 & 071 & h20v10 & Savannas & 04 & 24 & 2005 & 04 & 23 & 2005 \\
\hline 233 & 064 & h11v09 & Broadleaf evergreen forests & 07 & 11 & 2005 & 07 & 12 & 2005 \\
\hline 013 & 030 & h12v04 & Deciduous broadleaf forests & 09 & 24 & 2005 & 09 & 22 & 2005 \\
\hline 035 & 020 & h12v03 & Evergreen needleleaf forests & 09 & 23 & 2004 & 09 & 21 & 2004 \\
\hline 132 & 019 & h23v03 & Deciduous needleleaf forests & 07 & 30 & 2007 & 07 & 28 & 2007 \\
\hline
\end{tabular}

where many natural resources management decisions are made. Highresolution LAI data are also of interest to NASA's strategic roadmap to scientific objectives relating to atmospheric composition, climate and weather, and the hydrological cycle. In the development of applied science efforts, a 30-m Landsat-based LAI could have an especially large influence for studies at the scale of individual watersheds that deal with water resource management, carbon sequestration, and air pollution and erosion studies, among others.

The Landsat Data Distribution Policy, under the auspices of the United Stated Geological Survey (USGS) Earth Resources Observation and Science Center (EROS) and NASA, provides Level 1 terrain-corrected data for the entire U.S. Landsat archive and globally at no charge (Chander et al., 2009a; Woodcock et al., 2008). The Landsat series of sensors, including the Multispectral Scanner (MSS), Thematic Mapper (TM) and Enhanced Thematic Mapper Plus (ETM+), represent the only existing multidecadal assets for monitoring natural and human-induced landscape changes over months, years and decades for land units on the order of tens of meters. The TM and ETM + sensors in particular have been used extensively for monitoring and land change studies over smaller regions because of their enhanced spatial, spectral, radiometric, and geometric performance over the MSS sensor (Chander et al., 2009b; Roy et al., 2010). The utility of the long-term Landsat archive has not been fully assessed, although regional- to continental-scale multi-temporal mosaics of Landsat data have been constructed for pilot studies of national landuse change monitoring and disturbance mapping (Hansen et al., 2008; Wulder et al., 2002). The Global Land Survey (GLS) decadal Landsat data set now provides relatively cloud-free acquisitions for each available Landsat scene for the 1970s, 1990s and 2000s (Gutman et al., 2008).

Many studies have used Landsat data to estimate LAI through empirical relations between field-measured values of LAI and vegetation indices, but these studies, while performing over local regions and over a shorter time frame, have limited applicability at continental

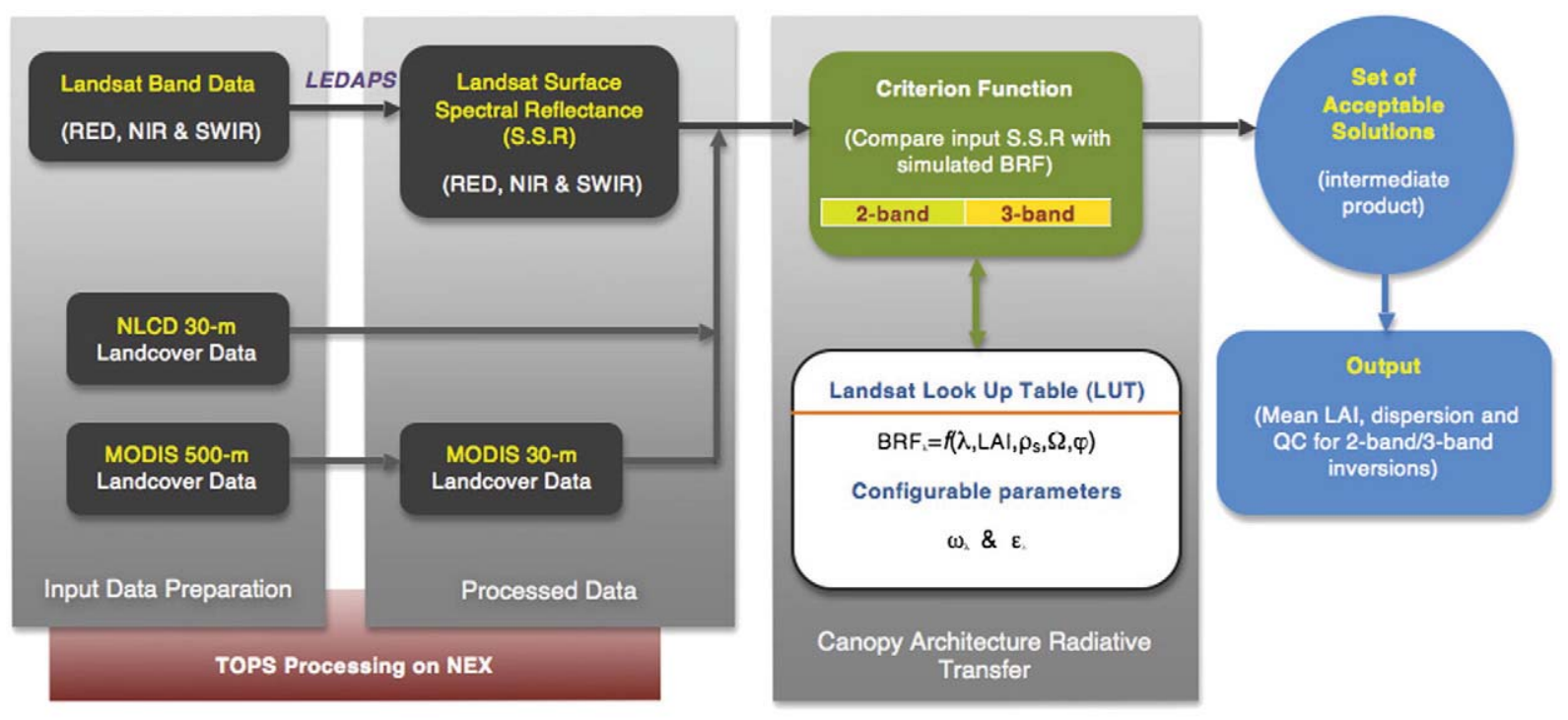

BRF = Bidirectional Reflectance Factor; LAI= Leaf Area Index; QC= Quality Control.

$\mathrm{NIR}=$ Near-infrared $;$ SWIR= Short-wave infrared.

LEDAPS $=$ Landsat Ecosystem Disturbance Adaptive Processing System.

TOPS $=$ Terrestrial Observation and Prediction System.

NEX $=$ NASA Earth Exchange

$\lambda=$ wavelength; $\rho=$ soil reflectance; $\Omega=$ view geometry; $\varphi=$ illumination geometry;

Fig. 1. A schematic showing the processes involved in a Landsat 30-m LAI algorithm. The "Input Data Preparation" gray shaded box identifies the basic input data that are required for the retrieval process. The TOPS processing framework is utilized to process the input data on the NASA Earth Exchange (NEX) platform. Processing involves components related to atmospheric correction using the LEDAPS framework and reprojection/resampling routines. The "Canopy Architecture Radiative Transfer (CART)" box shows the main elements involved in the physical retrieval process. CART simulates the BRF as a function of wavelength, LAI, view and illumination geometry and soil reflectances, given the two important configurable parameters, i.e., the single scattering albedo and the relative uncertainties in the reflectance bands. 
Table 2

Remapping of the NLCD 2001 land cover map.

\begin{tabular}{ll}
\hline NLCD 2001 native classes & NLCD 2001 remapped/merged classes ${ }^{\mathrm{a}}$ \\
\hline $\mathrm{NLCD}=11,12$ & 254 \\
$\mathrm{NLCD}=31,32$ & 255 \\
$\mathrm{NLCD}=42,43$ & 5 or 7 (depending on location) \\
$\mathrm{NLCD}=41$ & 6 or 8 (depending on location) \\
$\mathrm{NLCD}=90,95$ & 4 \\
$\mathrm{NLCD}=21,22,23$ & 4 \\
$\mathrm{NLCD}=82$ & 3 \\
$\mathrm{NLCD}=51,52$ & 2 \\
$\mathrm{NLCD}=71,72,73,74,81$ & 1
\end{tabular}

a The remapped/merged class numbers ( 1 to 8 ) refer to the LAI/FPAR based classification scheme present in the MCD12Q1 land cover product. 254 refers to water and perennial snow. 255 refers unvegetated or barren land. $1=$ grasses/cereal crops; $2=$ shrubs; $3=$ broadleaf crops; $4=$ savanna; $5=$ evergreen broadleaf forest; $6=$ deciduous broadleaf forest; $7=\mathrm{ev}-$ ergreen needleleaf forest; and $8=$ deciduous needleleaf forest. The NLCD 2001 native class definitions are described in Table 1 of Homer et al., 2004.

or global scale (Baret et al., 2007; Butson \& Fernandes, 2004; Myneni et al., 1997; Sellers et al., 1996; Spanner et al., 1990; Wang et al., 2004). A physically based model to describe the propagation of light in plant canopies and its use in retrieval of biophysical parameters has the potential for a more widely applicable algorithm. Most physical algorithms are rooted in the principles of reflectance model inversion and operated through minimizing a merit function. Such a function yields a value for LAI by minimizing the summed differences between simulated and measured reflectances for all wavelengths (Knyazikhin et al., 1998; Kuusk \& Nilson, 2000; Rautiainen, 2005). While estimating LAI from reflectance-based inversion with Landsat data for local regions is not a new concept (Fang \& Liang, 2003; González-Sanpedro et al., 2008), physical algorithms for the operational estimation of Landsat-based LAI for regional to continental scale are presently lacking.

The objectives of this study are to formulate and demonstrate a physically based LAI retrieval technique at the Landsat sensor resolution. Due to the limited availability of spatial and temporal fieldbased measurements, the accuracy of the 30-m LAI retrieval from the TM imagery will not be addressed in this paper, but a validation exercise with available field based measurements is an immediate priority. This study is limited to the algorithm development and characterization of input parameters that are key in prototyping a Landsat-based LAI algorithm. The paper is organized as follows: Section 2 formulates the theoretical basis of the LAI retrieval algorithm at a Landsat resolution; Section 3 describes the input data utilized in this research study and methods related to processing of surface reflectances and LAI production; Sections 4.1-4.3 present a comparative analysis of Landsat and MODIS reflectances and corresponding LAI retrievals over selected regions representing different

Table 3

Input data layers used in this study.

\begin{tabular}{|c|c|c|c|c|}
\hline & $\begin{array}{l}\text { Sensor/data } \\
\text { source }\end{array}$ & Products & Spatial resolution & $\begin{array}{l}\text { Temporal } \\
\text { resolution }\end{array}$ \\
\hline \multirow[t]{4}{*}{$\begin{array}{c}\text { Reflectance } \\
\text { products }\end{array}$} & \multirow[t]{2}{*}{ MODIS } & $\begin{array}{l}\text { MCD43A4 } \\
(\text { RED, NIR) }\end{array}$ & $500 \mathrm{~m}$ & 8-day \\
\hline & & $\begin{array}{l}\text { MCD43A4 } \\
\text { (RED, NIR) }\end{array}$ & $30 \mathrm{~m}$ (resampled) & 8-day \\
\hline & $\begin{array}{l}\text { Landsat } \\
(\mathrm{TM} \text { and } \mathrm{ETM}+)\end{array}$ & $\begin{array}{l}\text { GLS } 2005 \\
\text { (RED, NIR, } \\
\text { and SWIR) }\end{array}$ & $30 \mathrm{~m}$ & Daily \\
\hline & $\begin{array}{l}\text { Landsat } \\
(\mathrm{TM} \text { and ETM +) }\end{array}$ & $\begin{array}{l}\text { GLS } 2005 \\
\text { (RED, NIR, } \\
\text { and SWIR) }\end{array}$ & $\begin{array}{l}\text { 50-, 100-, 250-, } \\
\text { 500-m (resampled) }\end{array}$ & Daily \\
\hline $\begin{array}{c}\text { Biophysical } \\
\text { products }\end{array}$ & MODIS & $\begin{array}{l}\text { MOD15A2 } \\
\text { (LAI) }\end{array}$ & $\begin{array}{l}500 \mathrm{~m} \text { (resampled from } \\
1 \mathrm{~km} \text { standard product) }\end{array}$ & 8-day \\
\hline Land-cover & MODIS & MCD12Q1 & $500 \mathrm{~m}$ & Yearly \\
\hline map & NLCD & NLCD 2001 & $30 \mathrm{~m}$ & Yearly \\
\hline
\end{tabular}

Table 4

Single scattering albedo and RED threshold value used to parameterize the LAl algorithm.

\begin{tabular}{lllll}
\hline Biome type & $\omega_{\text {RED }}$ & $\omega_{\text {NIR }}$ & $\omega_{\text {SWIR }}$ & RED $_{\text {THRES }}$ \\
\hline Grasses and cereal crops & 0.18 & 0.76 & 0.78 & 0.18 \\
Shrubs & 0.13 & 0.85 & 0.76 & 0.40 \\
Broadleaf crops & 0.11 & 0.90 & 0.70 & 0.20 \\
Savannas & 0.12 & 0.86 & 0.76 & 0.20 \\
Evergreen broadleaf forests (EBF) & 0.14 & 0.83 & 0.78 & 0.12 \\
Deciduous broadleaf forests (DBF) & 0.14 & 0.90 & 0.40 & 0.07 \\
Evergreen needleleaf forests (ENF) & 0.15 & 0.88 & 0.40 & 0.07 \\
Deciduous needleleaf forests (DNF) & 0.15 & 0.86 & 0.40 & 0.06 \\
\hline
\end{tabular}

land cover types, and Section 4.4 provides a pilot implementation of the LAI algorithm to create a 30-m LAI map for the state of California utilizing the GLS 2005 Landsat data archive.

\section{Theoretical formulation}

The development of an operational physical algorithm for retrieving a biophysical parameter should take into account the uncertainties involved in the modeling phase as well as the uncertainties present in the input data. Characterizing surface reflectances is a prerequisite in deriving higher-level biophysical products like LAI. Spectral reflectances from different sensors show characteristic bias in their magnitude response and orientation in the spectral plane due to differences in: (a) purity of the pixel containing a target (mixture vs. pure classes); (b) spectral differences in the wavelength bandwidth; (c) viewing and illumination geometry; (d) pre-calibration and/or atmospheric correction procedures if any; and (e) geolocation uncertainties. Computation of surface reflectance is a three-step process that involves calculating the initial at-sensor spectral radiance, the top-of-atmosphere (TOA) reflectance, and the surface spectral reflectance after atmospheric correction of TOA reflectance. Each of these steps introduces uncertainties that propagate in the computational chain and hence comparison with field obtained measurements can yield significant differences in complex terrain and sub-optimal atmospheric conditions, such as high aerosol levels. Calculation of at-sensor spectral radiance involves radiometric calibration that can contain errors in the rescaling gain and bias values. Further, bias in the spectral radiance at the sensor's aperture can introduce errors in the TOA reflectance that propagate through to the estimation of surface spectral reflectances after atmospheric correction procedures. In addition, the atmospheric correction procedures involve a suite of approximations related to different modeling techniques (dark object subtraction, radiative transfer modeling, etc.; Butson \& Fernandes, 2004).

Generally, two key factors influence the quality of LAI retrievals: 1) uncertainties in the input to the algorithm (surface reflectances and land cover); and 2) model uncertainties, namely, the consistency between simulated surface reflectances and the corresponding sensor-observed surface reflectances. In the following sub-sections, we formulate the physical model for parameterizing the canopy spectral reflectance to derive the Bidirectional Reflectance Factor (BRF) as a function of LAI, soil type, view geometry and also account for the variability in sensor wavelength and spatial resolution. Subsequently, we formulate the LAI retrieval algorithm at the Landsat resolution for dominant biome types utilizing better land cover characterization and extending the physical model via adjusting key parameters to attain consistency in observed versus modeled surface reflectances.

\subsection{Parameterization of canopy spectral reflectance}

The theory of canopy spectral invariants (Huang et al., 2007; Knyazikhin et al., 2010) is used to formulate surface reflectance, 



Fig. 2. Spatial aggregation of Landsat reflectances at different spatial resolution (50-, 100-, 250- and 500-m) for tiles representing (a) grasslands (h10v05), (b) shrubland (h08v05), (c) deciduous broadleaf forest (h12v04) and (d) deciduous needleleaf forest (h23v03). Reflectances are plotted for pixels delineated by the MODIS C5 landcover map (also scaled at different resolutions).

specifically the bidirectional reflectance factor (BRF), via a small set of spectral and structural parameters that characterize the spectral response of vegetation canopies at varying spatial scales (Huang et al., 2007; Lewis \& Disney, 2007; Smolander \& Stenberg, 2005; Wang et al., 2003). First-order approximation of the BRF for a vegetation canopy bounded below by a nonreflecting surface (Ganguly et al., 2008a; Huang et al., 2007) is approximated as

$B R F_{B S, \lambda}(\Omega)=\omega_{\lambda} R_{1}(\Omega)+\frac{\omega_{\lambda}^{2}}{1-p \omega_{\lambda}} R_{2}(\Omega)$,

where $B R F_{B S, \lambda}$ is the bidirectional reflectance factor for a nonreflecting black soil surface, $\Omega$ is the direction of photon escape after interaction with phytoelements, $\omega_{\lambda}$ is the leaf single scattering albedo and $p$ refers to the recollision probability, which is defined as the probability that a photon scattered by a foliage element in the canopy will interact within the canopy again. Assuming that a scattered photon can escape the canopy through the upper and lower boundary with probabilities $\eta$ (assuming that the probability $\eta$ remains constant in successive photon interactions) and $\tau$, respectively and $\eta+\tau+p=1$, then $R_{1}=\eta i_{0}$ and refers to portion of photons from the incident flux that escape the canopy in upward directions as a result of one interaction, and $R_{2}=\eta p i_{0}$, which accounts for photons that have undergone two or more interactions (Huang et al., 2007). Here $i_{0}$ is the probability of initial collisions, or canopy interceptance, defined as the portion of photons from the incident flux that are intercepted by the foliage elements for the first time. The probabilities depend only on canopy structural attributes, and hence are termed "spectral invariants." The spectral absorptance, $a_{B S, \lambda}$ of the vegetation canopy with non-reflecting background can be expressed as

$a_{B S, \lambda}=\frac{1-\omega_{\lambda}}{1-p \omega_{\lambda}} i_{0}$

The fraction of photosynthetically active radiation absorbed (FPAR) is a weighted integral of Eq. (2) over the photosynthetically active radiation (PAR, 400-700 nm) spectral region (Knyazikhin et al., 1998). The formulation in Eq. (1) permits decoupling of the structural and radiometric components of any optical sensor signal and requires a set of sensor-specific values of configurable parameters, namely the single scattering albedo and uncertainties in surface reflectances, in order to maintain consistency in retrieved LAI (Ganguly et al., 2008a). The scalable properties in the formulation will be utilized in this research to model the BRF at a scale representative of the Landsat resolution.

The solution of the radiative transfer equation for a vegetation medium is constructed from the solution of two sub-problems to which the notion of spectral invariance can be directly applied (Knyazikhin 

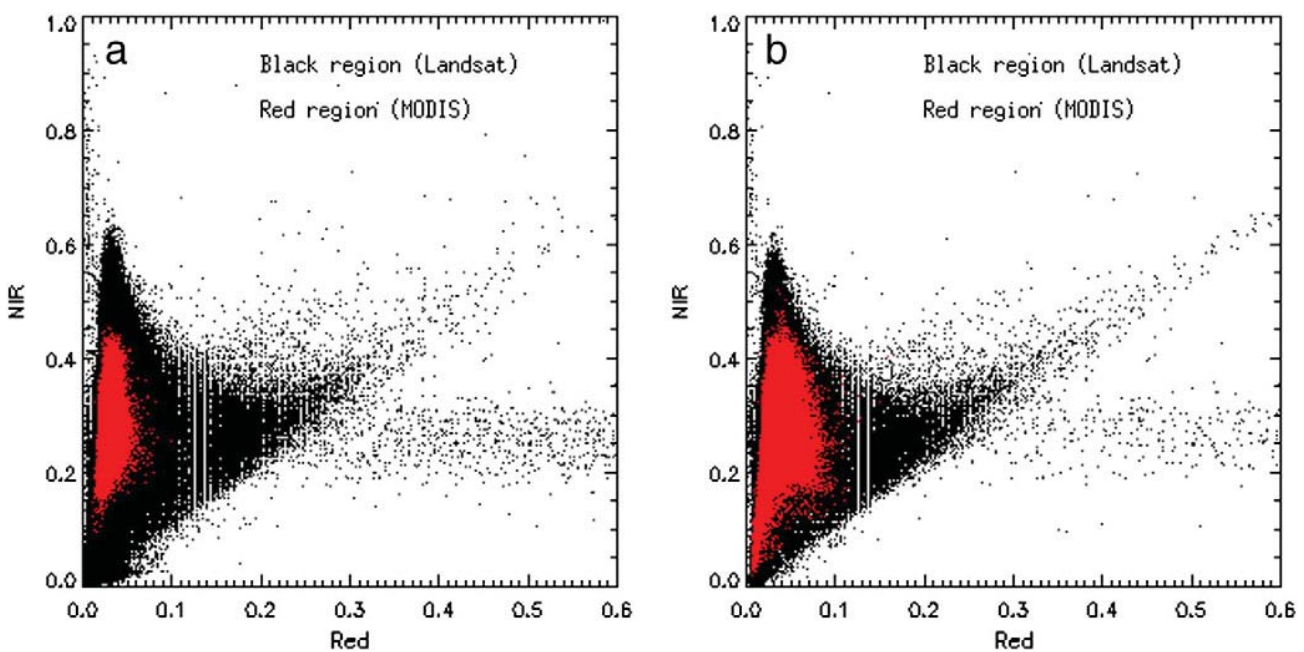

Fig. 3. (a) Landsat and MODIS reflectances at 30-m using MODIS downsampled 30-m land cover map for a homogeneous region represented by broadleaf deciduous forest at Harvard forest (Landsat tile path/row: 130/30). (b) Same as (a) but using NLCD 30-m land cover. The forest pixels are classified as biome-type 6 (LAI/FPAR based classification scheme in the MCD12Q1 land cover product) and with Landsat RED/NIR reflectances greater than 0 and less than equal to 1 . The NLCD classes belonging to class number 41 represent the deciduous forest category and are used for (b).

\& Marshak, 2000): (1) the black soil (BS) problem: the original illumination condition at the top of the canopy and the soil assumed to be absolutely absorbing; and (2) the soil (S) problem: there is no input energy from above, but a Lambertian energy source is located at the bottom of the canopy. This decomposition technique was implemented in the MODIS LAI/FPAR operational algorithm (Knyazikhin
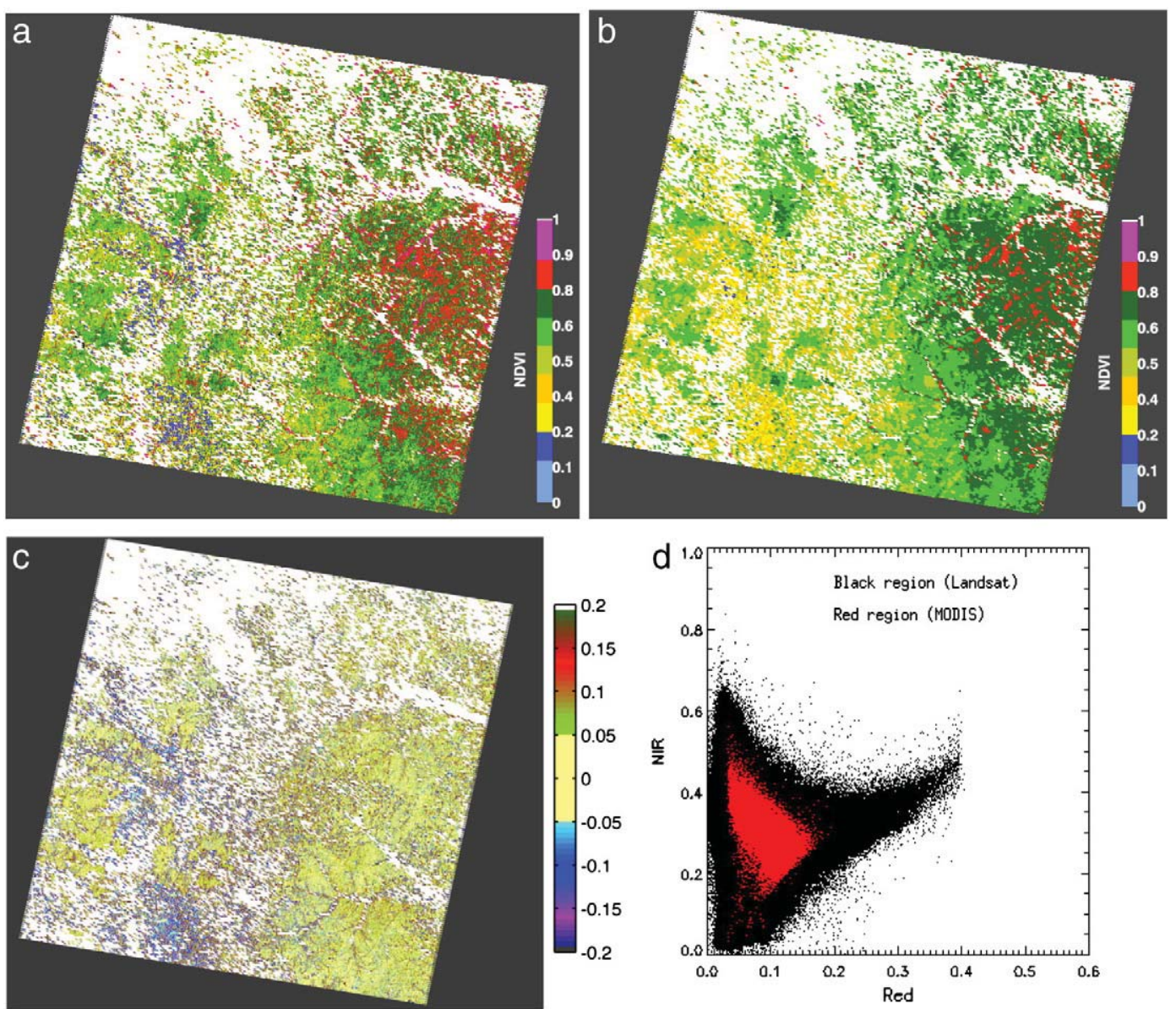

Fig. 4. (a) Landsat-derived NDVI for pixels classified as grasslands (Landsat tile path/row: 29/33, representing a homogeneous grassland site at Kansas Prarie). (b) Same as (a) but showing MODIS NDVI (reflectances downsampled to 30-m and re-projected to the Landsat specifications). The Landsat scene falls on MODIS tile h10v05. (c) 30-m NDVI difference map between Landsat and MODIS. (d) RED and NIR cross-plot for the grassland pixels as shown in (a) and (b). The MODIS land cover map is downsampled to 30-m and re-projected to Landsat for this analysis. The time of acquisition for the Landsat scene is 23rd July, 2005. 

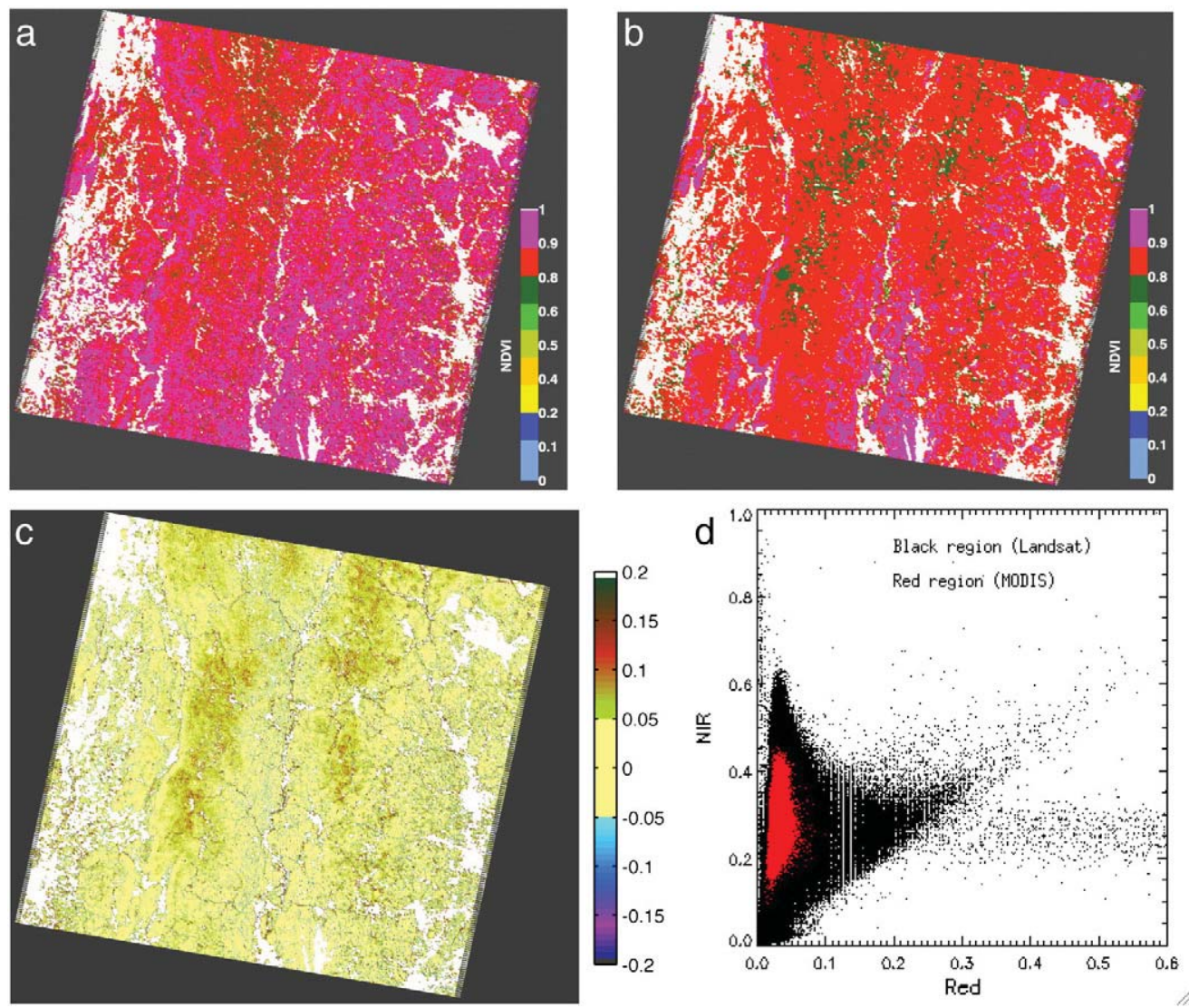

Fig. 5. (a) Landsat-derived NDVI for pixels classified as broadleaf deciduous forests (Landsat tile path/row: 13/30, representing a homogeneous forest site at Harvard forest). (b) Same as (a) but showing MODIS NDVI (reflectances downsampled to 30-m and re-projected to the Landsat specifications). The Landsat scene falls on MODIS tile h12v04. (c) 30-m NDVI difference map between Landsat and MODIS. (d) RED and NIR cross-plot for the BDF pixels as shown in (a) and (b). The MODIS land cover map is downsampled to $30-\mathrm{m}$ and re-projected to Landsat for this analysis. The time of acquisition for the Landsat scene is 24 th September, 2005.

et al., 1998). According to this approach, the spectral BRF and canopy spectral absorptance are approximated as

$B R F_{\lambda}(\Omega)=B R F_{B S, \lambda}(\Omega)+\frac{\rho_{\text {sur }, \lambda}}{1-\rho_{\text {sur }, \lambda} r_{S, \lambda}} t_{B S, \lambda} J_{S, \lambda}(\Omega)$,

$a_{\lambda}=a_{B S, \lambda}+\frac{\rho_{\text {sur }, \lambda}}{1-\rho_{s u r, \lambda} r_{S, \lambda}} t_{B S, \lambda} a_{S, \lambda}$,

where the second term on the right hand side of Eqs. (3) and (4) describes the contribution to the BRF and absorptance from multiple interactions between the ground and vegetation. Here, $\rho_{\text {sur }, \lambda}$ is an effective ground reflectance (Knyazikhin et al., 1998) which represents the fraction of radiation reflected by the canopy ground and its range of variation does not exceed the range of variation of the hemispherically integrated bidirectional factor of the ground surface. The set, representing various patterns of effective ground reflectances at different wavelengths, contains 29 patterns of reflectances ranging from bright to dark (Baret et al., 1993; Jacquemond et al., 1992). While calculation of ground reflectances based on simplifying assumptions may be a weak point, the alternative, utilizing understory spectral databases (e.g. Kuusk et al., 2004; Peltoniemi et al., 2005) to characterize the background contribution for LAI retrievals for continental or global extents would be a significantly more demanding task as (a) there can be large variations in understory reflectances even within the same biome type, (b) variability of background reflectances is present at specific wavelengths across different regions, and (c) seasonal variations of background composition and their optical properties would comprise an added challenge. $t_{\mathrm{BS}, \lambda}$ is the transmittance of the vegetated canopy for the BS-problem. Variables $r_{\mathrm{S}, \lambda}$ and $J_{\mathrm{S}, \lambda}(\Omega)$ represent solutions to the "S-problem," where $r_{\mathrm{S}, \lambda}$ is the hemispherically integrated canopy reflectance and $J_{S, \lambda}(\Omega)$ is the radiance generated by isotropic sources $(1 / \pi)$ at the canopy bottom in a given direction $\Omega$ (Knyazikhin et al., 1998; 2005). The characterization of understory reflectance behavior with $\rho_{\text {sur }, \lambda}$ does not explicitly account for a moss or litter layer covering the soil, however the reflectance resulting from an anisotropic source $\left(r_{\mathrm{S}, \lambda}\right)$ with its characteristic $\rho_{\mathrm{sur}, \lambda}$ can be a property of the lowest layer of vegetation. Similar to Eq. (1), the first order approximation for the successive orders of scattering is also applicable to the "S problem" and allows variables $r_{\mathrm{S}, \lambda}, J_{\mathrm{S}, \lambda}(\Omega)$ and $t_{\mathrm{BS}, \lambda}$ to be approximated as

$r_{S, \lambda}=\omega_{\lambda} \bar{R}_{1, S}+\frac{\omega_{\lambda}^{2} \bar{R}_{2, S}}{1-p \omega_{\lambda}}$

$J_{S, \lambda}(\Omega)=J_{0}+\omega_{\lambda} J_{1}(\Omega)+\frac{\omega_{\lambda}^{2} J_{2}(\Omega)}{1-p_{J} \omega_{\lambda}}$,

$t_{B S, \lambda}(\Omega)=t_{0}+\omega_{\lambda} T_{1}(\Omega)+\frac{\omega_{\lambda}^{2} T_{2}(\Omega)}{1-p_{t} \omega_{\lambda}}$.

Here, $t_{0}$ is the zero-order direct transmittance, $T_{1}(\Omega)=\tau_{1}(\Omega) i_{0}$ and $T_{2}(\Omega)=\tau_{2}(\Omega) i_{0} . \tau_{1}$ and $\tau_{2}$ are probabilities that the scattered 


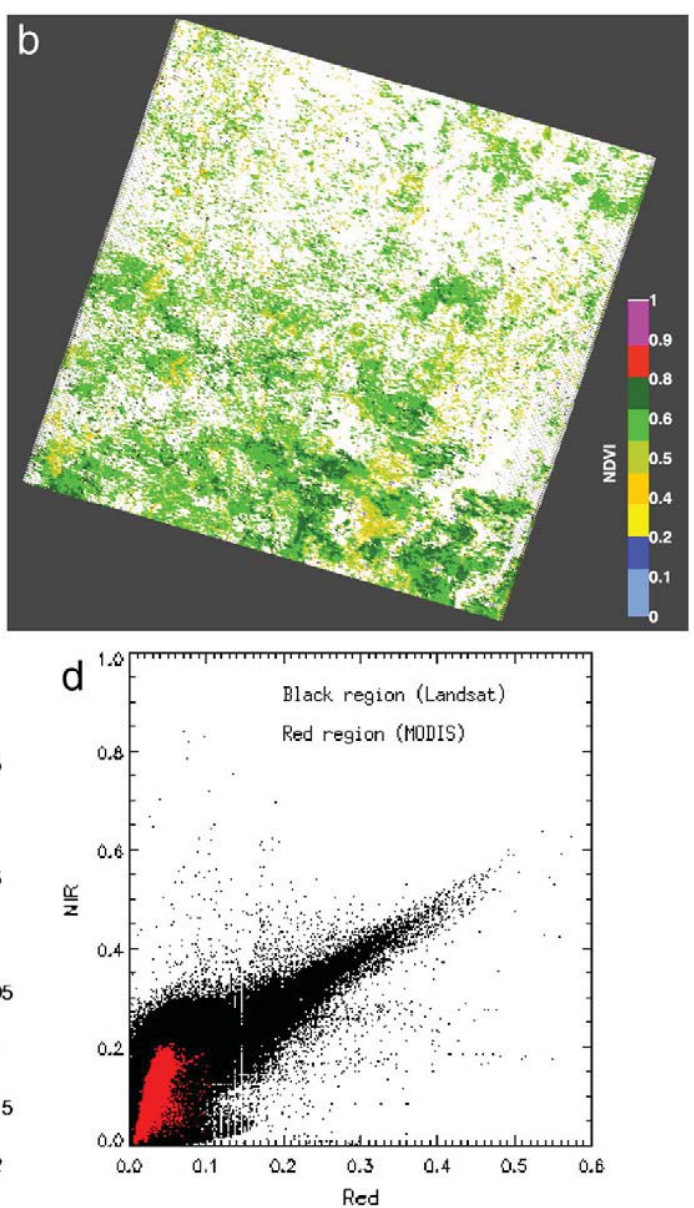

Fig. 6. (a) Landsat-derived NDVI for pixels classified as evergreen needleleaf forests (Landsat tile path/row: 35/20, representing a homogeneous forest site at Watson Lake, Canada). (b) Same as (a) but showing MODIS NDVI (reflectances downsampled to 30-m and re-projected to the Landsat specifications). The Landsat scene falls on MODIS tile h12v03. (c) 30-m NDVI difference map between Landsat and MODIS. (d) RED and NIR cross-plot for the ENF pixels as shown in (a) and (b). The MODIS land cover map is downsampled to 30-m and re-projected to Landsat for this analysis. The time of acquisition for the Landsat scene is 23rd September, 2004.

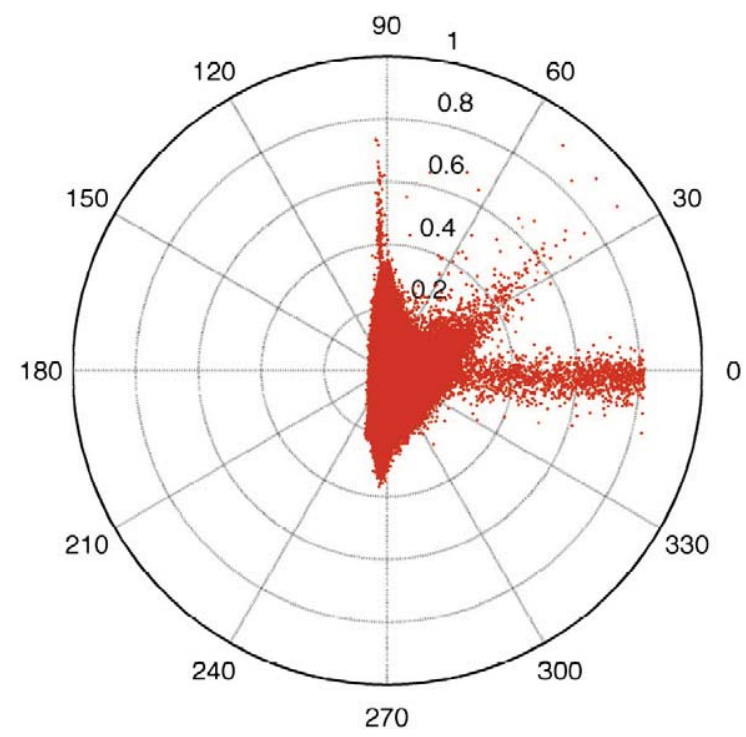

Fig. 7. Polar plot showing direction and magnitude of reflectance differences (RED and NIR from Landsat and MODIS) for broadleaf deciduous forests (cf. Fig. 6). The right lower and upper quadrants in the polar plot show a majority of pixels with difference magnitudes greater than zero and angles between $\pm 45^{\circ}$. This suggests that for Landsat pixels, difference angular vector lies below $45^{\circ}$, coordinates of reflectance pairs are localized in a lower LAI isoline relative to MODIS. photons can escape the lower boundary of the canopy. $J_{0} J_{1}(\Omega)$ and $J_{2}(\Omega)$ are analogous to $t_{0}, T_{1}(\Omega)$ and $T_{2}(\Omega)$. The analytical expression in Eq. (3) can thus be expanded as

$$
\begin{aligned}
B R F_{\lambda}(\Omega) & \\
= & \left\{\omega_{\lambda} R_{1}(\Omega)+\frac{\omega_{\lambda}^{2}}{1-p \omega_{\lambda}} R_{2}(\Omega)\right\} \\
& +\left\{\frac{\rho_{\text {sur }, \lambda} \cdot\left(t_{0}+\omega_{\lambda} T_{1}(\Omega)+\frac{\omega_{\lambda}^{2}}{1-p_{t} \omega_{\lambda}} T_{2}(\Omega)\right) \cdot\left(J_{0}+\omega_{\lambda} J_{1}(\Omega)+\frac{\omega_{\lambda}^{2}}{1-p_{j} \omega_{\lambda}} J_{2}(\Omega)\right)}{1-\rho_{\text {sur }, \lambda} \cdot\left(\omega_{\lambda} \bar{R}_{1, S}+\frac{\omega_{\lambda}^{2}}{1-p \omega_{\lambda}} \bar{R}_{2, S(\Omega)}\right)}\right\} .
\end{aligned}
$$

\subsection{Generation of spectral BRF and LAI retrieval at the Landsat resolution}

In accordance with the Collection 5 MODIS LAI/FAR algorithm (Myneni et al., 2002; Shabanov et al., 2005; Yang et al., 2006), the stochastic radiative transfer equation was used to generate the Collection 5 Look-up-Tables (LUT) - a set of tabulated BRF values (solutions of the "BS-problem" and "S-problem") as a function of single scattering albedo, for various LAI and sun-view geometries. For a given LAI and sun-view geometry, the spectrally invariant parameters are obtained by fitting the analytical approximations (cf. Eqs. 1-4) to their simulated counterparts. The parameters thus obtained are 

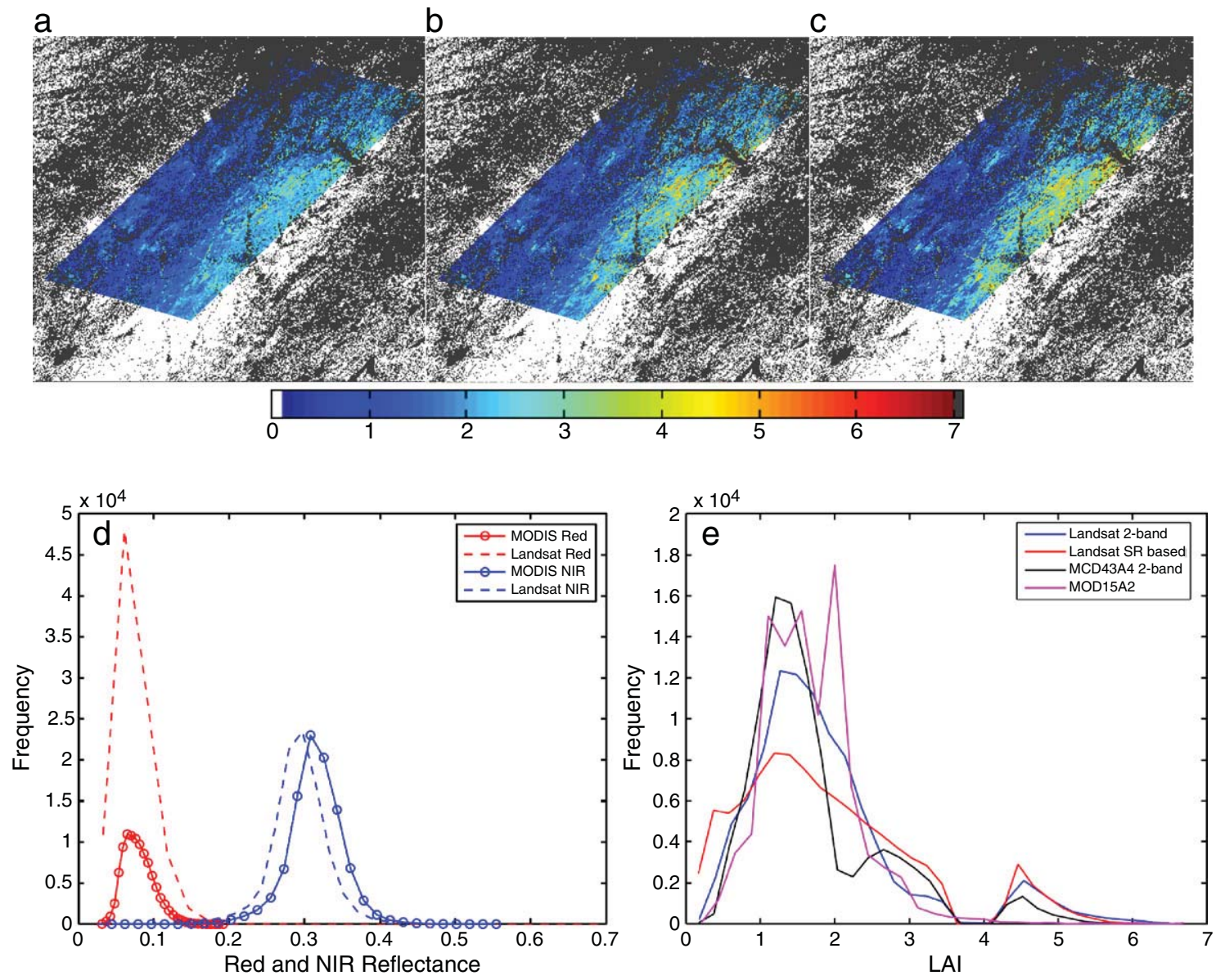

Fig. 8. (a) MOD15A2 LAI map for a homogeneous site representing grasslands in the Kansas Prairie, USA. The 500-m resampled Landsat scene with valid reflectances masks the region of interest and is superimposed in the MODIS tile h10v05. The backdrop represents the masked MODIS tile with white color denoting grassland pixels as classified by the MODIS land cover map and the gray pixels denoting all other values. (b) Same as (a) but showing Landsat-derived LAI with a 2-band inversion. (c) Same as (a) but showing Landsat-derived LAI by using the SR-LAI empirical rule. (d) Frequency distribution of RED and NIR values for MODIS (MCD43A4 product) and Landsat. (e) Frequency distribution of LAI from Landsat (2-band inversion and SR based), MCD43A4 (2-band inversion) and MOD15A2.

functions of LAI and sun-view geometry. To achieve accurate retrievals from a particular sensor like Landsat, the simulated surface reflectances (in the LUT) should be adjusted to be consistent with the expected range of the measured surface reflectances. The simulated surface reflectances are highly sensitive to leaf single scattering albedo for medium-to-high LAI and to soil reflectances for low LAI. The single scattering albedo is a function of spatial resolution and accounts for variation in BRF with sensor spatial resolution and spectral bandwidth (cf. Sections 4 and 5 of Ganguly et al., 2008a). Hence, a BRF can be computed for the sensor-specific resolution and spectral bands by adjusting the single scattering albedo. For Landsat, the initial set of single scattering albedos for the RED, NIR and SWIR bands were calculated for each biome (as classified by the MODIS LAI/FPAR biome classification scheme) as the mean single scattering albedo, such that

$\bar{\omega}=\int_{\alpha}^{\beta} \omega_{\lambda} f(\lambda) d \lambda$

where $f(\lambda)$ is the relative spectral response function for the Landsat spectral bands. $\alpha$ and $\beta$ represent the lower and upper bounds for wavelengths in the RED, NIR and SWIR bands and $\omega_{\lambda}$ for different biomes is obtained from field measured leaf spectral measurements (WWW1; Tian, 2004). $\omega_{\lambda}$ is further tuned to achieve the best possible overlap of simulated BRFs with Landsat-observed surface reflectances over a suite of biomes (Table 1 and Section 3.4). The specific values of $\bar{\omega}$ for the RED, NIR, and SWIR used in the 30-m algorithm are provided in Table 4. Given the spectrally invariant structural parameters, the BRF and absorptance for specific wavelengths are calculated using Eq. (8) with varying single scattering albedo and as a function of LAI and view geometry for the representative biomes. The dominant factors in classifying the biomes, based on RED, NIR, and SWIR bands, are soil reflectances and single scattering albedos in the respective bands.

The LAI retrieval algorithm exploits localization by attributing each point in the spectral space to a specific physical state that is characterized by a background brightness and LAI (e.g., Knyazikhin et al., 1998). A pixel can have a background ranging from dark to bright depending on the type of soil, and the LAI can vary over a range for each specific instance of background brightness. Given a Landsat pixel with a reflectance triplet (RED, NIR, SWIR), a merit function is used to select the set of acceptable solutions such that

$\Delta^{2}=\frac{\left(N I R-N I R^{*}\right)}{\sigma_{N I R}^{2}}+\frac{\left(R E D-R E D^{*}\right)}{\sigma_{R E D}^{2}}+\frac{\left(S W I R-S W I R^{*}\right)}{\sigma_{S W I R}^{2}}$,

Here, NIR, RED and SWIR denote values of measured surface reflectances, while $N I R^{*}, R E D^{*}$ and $S W I R^{*}$ correspond to simulated reflectances from the LUT. The dispersions $\sigma_{\text {NIR }}^{2}, \sigma_{R E D}^{2}$ and $\sigma_{S W I R}^{2}$ quantify combined model and observational uncertainties in NIR, RED and SWIR spectral bands and are configurable parameters in our approach (Wang et al., 2001). The dispersions are represented as $\sigma_{\text {NIR }}=\varepsilon_{N I R} \cdot N I R$, $\sigma_{R E D}=\varepsilon_{R E D} \cdot R E D$ and $\sigma_{S W I R}=\varepsilon_{S W I R} \cdot S W I R$, where $\varepsilon_{N I R}, \varepsilon_{R E D}$ and $\varepsilon_{S W I R}$ are 
a b
C

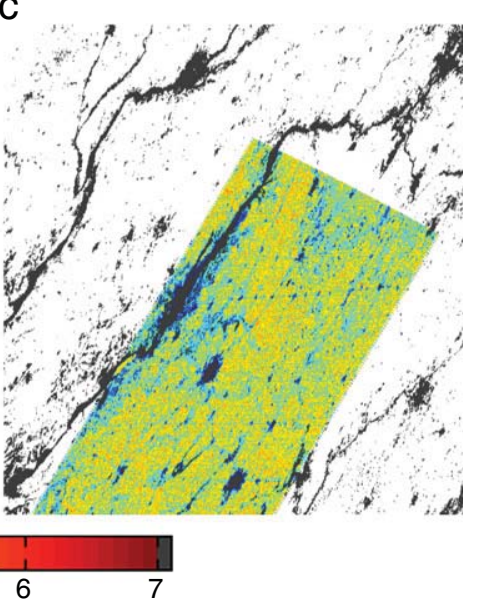

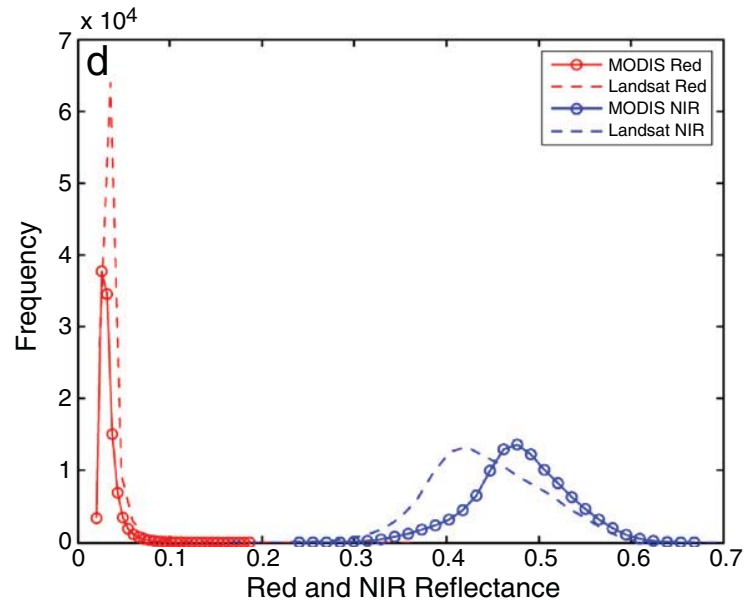



Fig. 9. (a) MOD15A2 LAI map for a homogeneous site representing broadleaf crops in Bondville, USA. The 500-m resampled Landsat scene with valid reflectances masks the region of interest and is superimposed in the MODIS tile h11v04. The backdrop represents the masked MODIS tile with white color denoting cropland pixels as classified by the MODIS land cover map and the gray pixels denoting all other values. (b) Same as (a) but showing Landsat-derived LAI with a 2-band inversion. (c) Same as (a) but showing Landsat-derived LAI by using the SR-LAI empirical rule. (d) Frequency distribution of RED and NIR values for MODIS (MCD43A4 product) and Landsat. (e) Frequency distribution of LAI from Landsat (2-band inversion and SR based), MCD43A4 (2-band inversion) and MOD15A2.

the corresponding relative uncertainties (Wang et al., 2001). Values of relative uncertainties, 30\% for RED and 15\% for NIR and SWIR, that are used in this study (Ganguly et al., 2008b) result in maximizing the retrieval index without loss of information content. The variable $\Delta^{2}$, characterizing the proximity of measured surface reflectances to simulated values, has a chi-square distribution with three degrees of freedom. A value of $\Delta^{2} \leq 3$ indicates good proximity between observations and simulations. All LAI and soil reflectance values satisfying this criterion constitute the set of acceptable solutions for a particular Landsat observation (NIR, RED and SWIR). In the situation when $\Delta^{2} \leq 3$ fails to localize a solution set, Eq. (10) reduces to a two-band (NIR and RED) merit function $\left(\Delta^{2} \leq 2\right)$. From this point on, we use the terminology "3-band" $\left(\Delta^{2} \leq 3\right)$ and "2-band" $\left(\Delta^{2} \leq 2\right)$ retrieval algorithm. A schematic diagram describing the processes in the LAI retrieval algorithm is shown in Fig. 1. The results from the algorithm are discussed in Section 4.3 and 4.4 .

\section{Data and methods}

Sections 3.1-3.3 describe the satellite-derived surface reflectance products, LAI data and land cover products and resampling methodologies undertaken to intercompare datasets. Sections 3.4 and 3.5 describe the methodology for retrieving LAI at both the MODIS and Landsat spatial scales.

\subsection{Satellite data}

The USGS EROS and NASA released the Global Land Survey (GLS) 2005 orthorectified Landsat data globally at a spatial resolution of 30-m. The GLS 2005 data has core acquisition dates from 2005 to 2006 and consists of both Landsat 5 and gap-filled Landsat 7 imagery (Gutman et al., 2008; http://landsat.usgs.gov/science_GLS2005.php). Each scene consists of a single, cloud-free acquisition, and the time of acquisition generally falls during leaf-on conditions for the location. Data recorded in 2004 and 2007 are used to fill areas of low image quality or excessive cloud cover. In this study, we used the GLS 2005 data for the scenes listed in Table 1 as well as 45 scenes that cover the state of California.

To aid our comparison between Landsat surface reflectances and derived LAI with its MODIS counterpart, we ingest the 8-day 500-m Collection 5 (C5) MODIS Nadir BRDF-Adjusted Reflectance (NBAR) product (MCD43A4; Schaaf et al., 2002; Roman et al., 2009) and the 8-day composited 1-km C5 MODIS LAI product (MOD15A2, Yang et al., 2006). The 8-day frequency of MOD15A2 arises from the MOD15A2 compositing algorithm, which assigns one best-quality LAI value to represent an 8-day period. Since the Landsat instruments always acquire imagery within $\pm 7.5^{\circ}$ of nadir, BRDF effects due to changing view angles is of minimal concern and comparison with the MODIS NBAR product, where view angle effects have been removed from the directional reflectances, is justified. The MOD15A2 
a

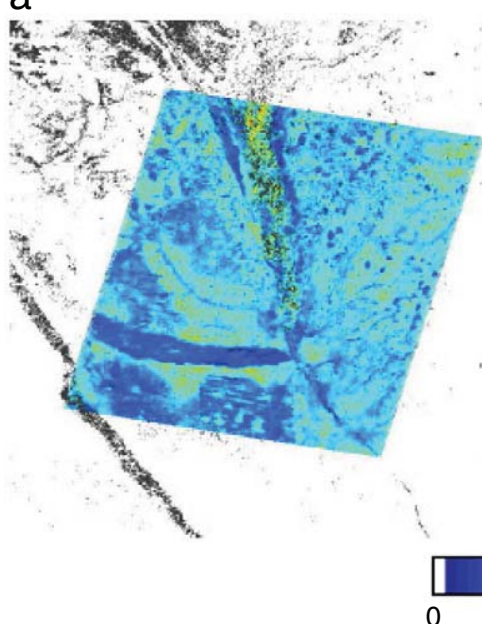

b

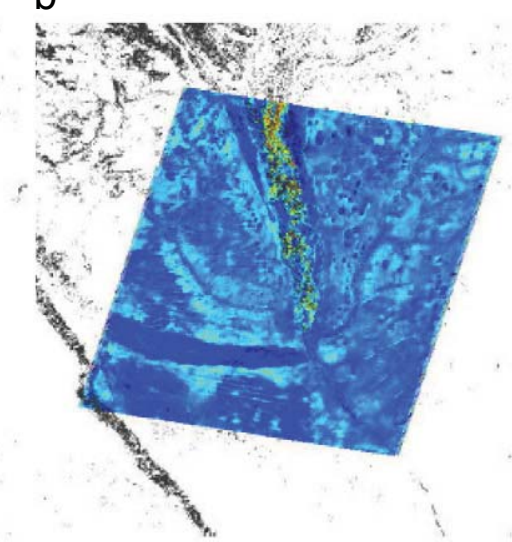

C

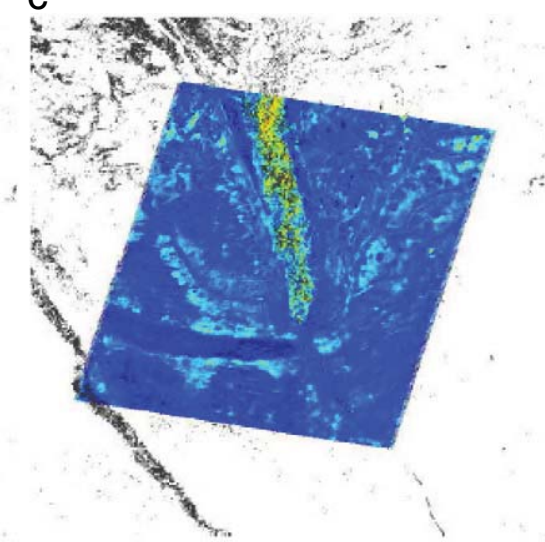

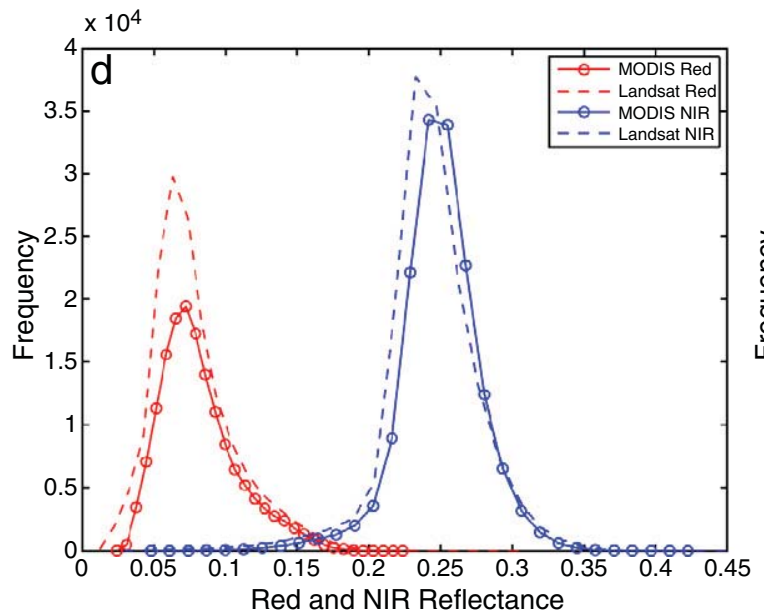

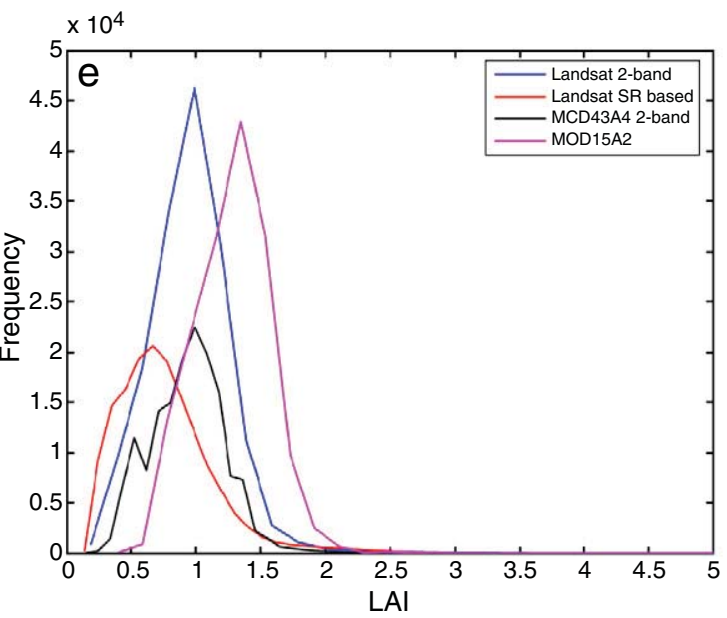

Fig. 10. (a) MOD15A2 LAI map for a homogeneous site representing savannas in Mongu, Zambia. The 500-m resampled Landsat scene with valid reflectances masks the region of interest and is superimposed in the MODIS tile h20v10. The backdrop represents the masked MODIS tile with white color denoting savanna pixels as classified by the MODIS land cover map and the gray pixels denoting all other values. (b) Same as (a) but showing Landsat-derived LAI with a 2-band inversion. (c) Same as (a) but showing Landsat-derived LAI by using the SR-LAI empirical rule. (d) Frequency distribution of RED and NIR values for MODIS (MCD43A4 product) and Landsat. (e) Frequency distribution of LAI from Landsat (2-band inversion and SR based), MCD43A4 (2-band inversion) and MOD15A2.

1 -km product is also resampled at a 500 -m spatial resolution using a nearest neighbor routine to prepare the data for comparative analysis as described in Section 4.3. We assume that there are negligible differences in the 500-m pixel leaf density behavior as compared to a $1 \mathrm{~km}$ pixel for grids representing homogeneous land cover type. This assumption is justified for the purpose of the analysis in Section 4.3. Additionally, the MCD43A4 product is also resampled and reprojected to a $30-\mathrm{m}$ grid to aid the analysis described in Section 4.1.

\subsection{Land cover data}

We use the National Land Cover Database (NLCD 2001), which provides accurate and consistent land cover for all the 50 states in the US at a spatial resolution of 30-m and with single-pixel land cover accuracies ranging from 73 to $77 \%$ (Homer et al., 2004). The use of a high-resolution land cover map is critical to this study, as a coarser land cover map would mean that a) a majority of pixels would represent a mixed pixel signal and b) retrieved LAI for a pixel can have huge biases due to errors in biome type representation. A remapping (or "cross-walking") of the NLCD vegetated classes to an eight-biome classification is performed to match the MODIS LAI/FPAR based 8-biome classification system (cf. Table 2). These biomes span structural variations along the horizontal (homogeneous vs. heterogeneous) and vertical (single- vs. multistory) dimensions, canopy height, leaf type, soil brightness and climate space for herbaceous and woody vegetation globally. The aggregated class map also reduces the number of unknowns of the inverse problem through the use of simplifying assumptions on the canopy architecture. The land cover classes that are structurally similar in nature (e.g. open shrublands and closed shrublands) have comparable characteristics in the RED-NIR spectral plane and the single scattering albedos in the RED and NIR bands are identical. The convergence of these classes into a more generic class is hence justified for a retrieval algorithm that can be generalized for a continental-to-global scale. A California-wide land cover mosaic is also created from the NLCD land cover mapping zones, which is used as an ancillary input in Section 3.4 for the 30-m LAI retrieval process.

The 500-m C5 MODIS land cover product (MCD12Q1, Friedl et al., 2010) is also used to analyze spatial scaling of spectral reflectances. The MCD12Q1 product is resampled to resolutions of 250-, 100-, 50- $\mathrm{m}$ and $30-\mathrm{m}$ for the MODIS tiles described in Table 1 using a nearest neighbor routine and re-projected to the Landsat projection scheme. The 8-day composite Day of Year (DOY) MODIS file nearest to the GLS acquisition time is selected for a consistent comparison (Table 1), assuming that during the 8-day period there are minimal land surface phenological changes. 
a

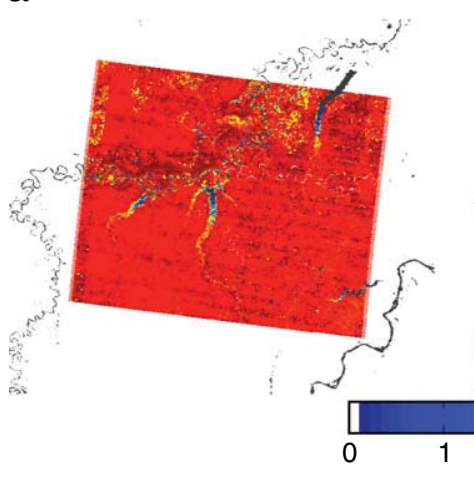

d

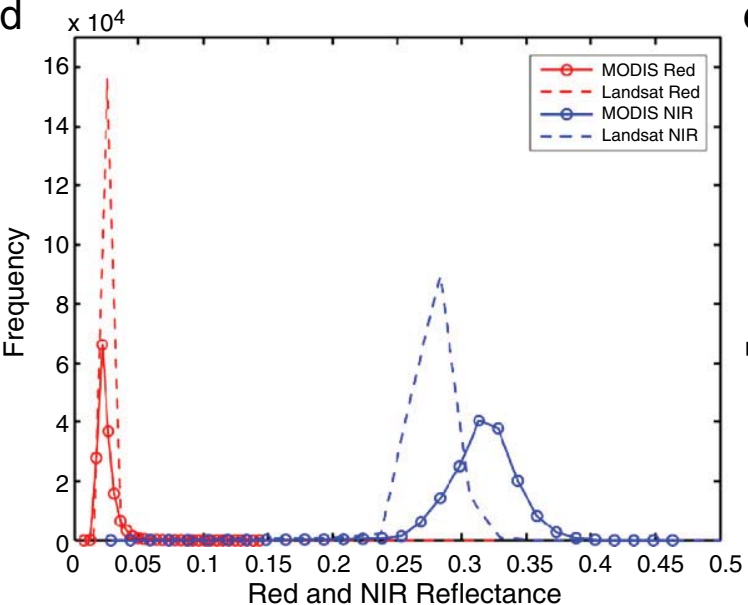

b

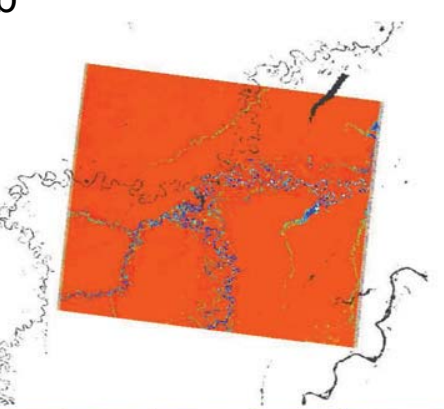

C

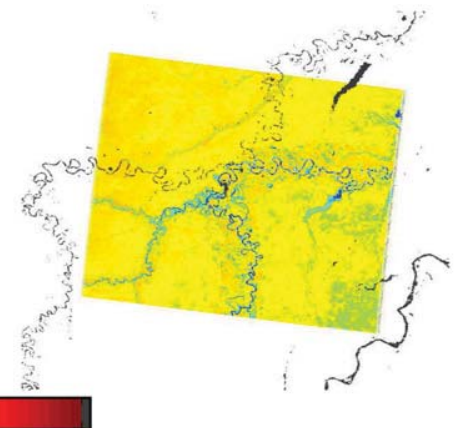

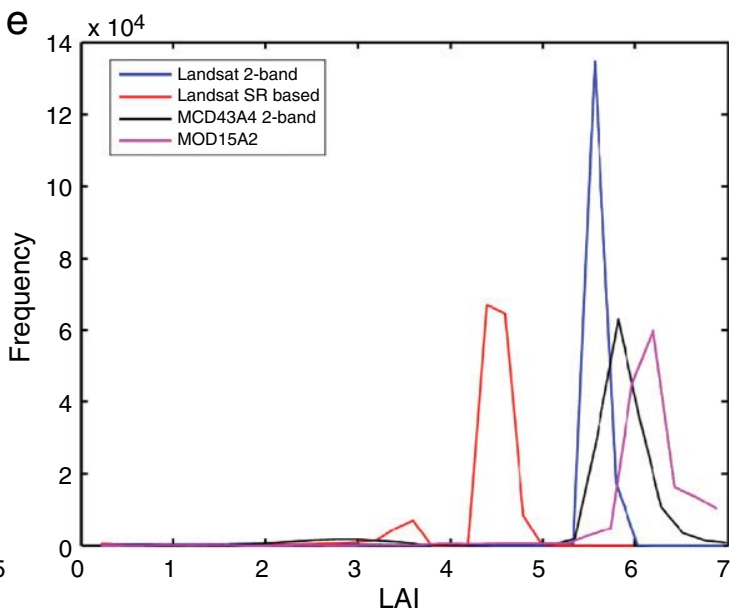

Fig. 11. (a) MOD15A2 LAI map for a homogeneous site representing broadleaf evergreen forests in the Amazon, South America. The 500-m resampled Landsat scene with valid reflectances masks the region of interest and is superimposed in the MODIS tile h11v09. The backdrop represents the masked MODIS tile with white color denoting broadleaf evergreen pixels as classified by the MODIS land cover map and the gray pixels denoting all other values. (b) Same as (a) but showing Landsat-derived LAI with a 2-band inversion. (c) Same as (a) but showing Landsat-derived LAI by using the SR-LAI empirical rule. (d) Frequency distribution of RED and NIR values for MODIS (MCD43A4 product) and Landsat. (e) Frequency distribution of LAI from Landsat (2-band inversion and SR based), MCD43A4 (2-band inversion) and MOD15A2.

\subsection{Landsat surface reflectance}

In generating surface reflectances from the native Landsat GLS data, we process scenes from the GLS 2005 Landsat 5 TM archive, which encompasses a wide-range of climate and land cover types (Table 1). In a comparative analysis with MODIS, the Landsat scenes are selected to represent biome-specific homogeneous regions within each MODIS tile (Table 1 ). In a separate exercise involving a pilot implementation of the LAI algorithm at 30-m scale, 45 Landsat 5 TM scenes that represent the state of California were also selected from the GLS data. Most of the California scenes are acquired during the peak of the growing season, resulting in spatial discontinuities when the scenes are mosaicked together (e.g. the growing season for crops near the San Francisco Bay Area peaks around April while adjacent scenes covering portions of the Sierra Nevada vegetations peaks later in the summer, are acquired in July or August). To rectify this issue, we harmonize the specific scenes to the same acquisition time (July-August) by replacing the April scene with other cloudfree Landsat 5 scenes from the same year. If no Landsat 5 scenes are available during the GLS acquisition time, we choose the previous year or the year after.

The Landsat Ecosystem Disturbance Adaptive Processing System (LEDAPS) framework is used to convert the GLS Landsat data to surface reflectances. Through the LEDAPS system, the raw data were calibrated to at-sensor radiance, converted to TOA reflectance, and then atmospherically corrected using the MODIS/6S methodology (Masek et al., 2006). Landsat surface reflectances that are derived from the TOA reflectances by the atmospheric correction routine assume that the target is lambertian and infinite and that the gaseous absorption and particle scattering in the atmosphere can be decoupled. The ancillary data used in the processing chain include gridded TOMS (Total Ozone Mapping Spectrometer) data, column water vapor from the NOAA NCEP reanalysis data, digital topography and NCEP surface pressure data. The dark, dense vegetation (DDV) type method is used to extract (AOD) optical depth directly from the imagery (Kaufman et al., 1997). Based on the physical correlation between chlorophyll absorption and bound water absorption, this method hypothesizes a linear relation between shortwave-infrared $(2.2 \mu \mathrm{m})$ surface reflectance (nearly unaffected by the atmosphere) and surface reflectance in the visible bands (Masek et al., 2006). The specific relations are derived from an analysis of data from Aerosol Robotic Network (AERONET) sites where AOD is measured directly (WWW2).

\subsubsection{Resampling of Landsat surface reflectance data}

The output from the LEDAPS provides surface spectral reflectances for all the available spectral bands with corresponding quality assurance (QA) flags for clouds, missing data, and an aerosol optical thickness map for the blue band. The RED, NIR and SWIR (band 5) spectral surface reflectances are used in our LAI algorithm. The 30-m spectral reflectances in RED and NIR are spatially aggregated to 50-, 100-, 250-, and 500-m respectively for the analysis detailed in Section 4.2. In order to compare LAI retrievals with MODIS (Section 4.3), the 30-m RED and NIR Landsat surface reflectances are spatially aggregated to match the MODIS $500-\mathrm{m}$ grid and reprojected to match the MODIS projection scheme for the scenes as described in Table 1. 
a

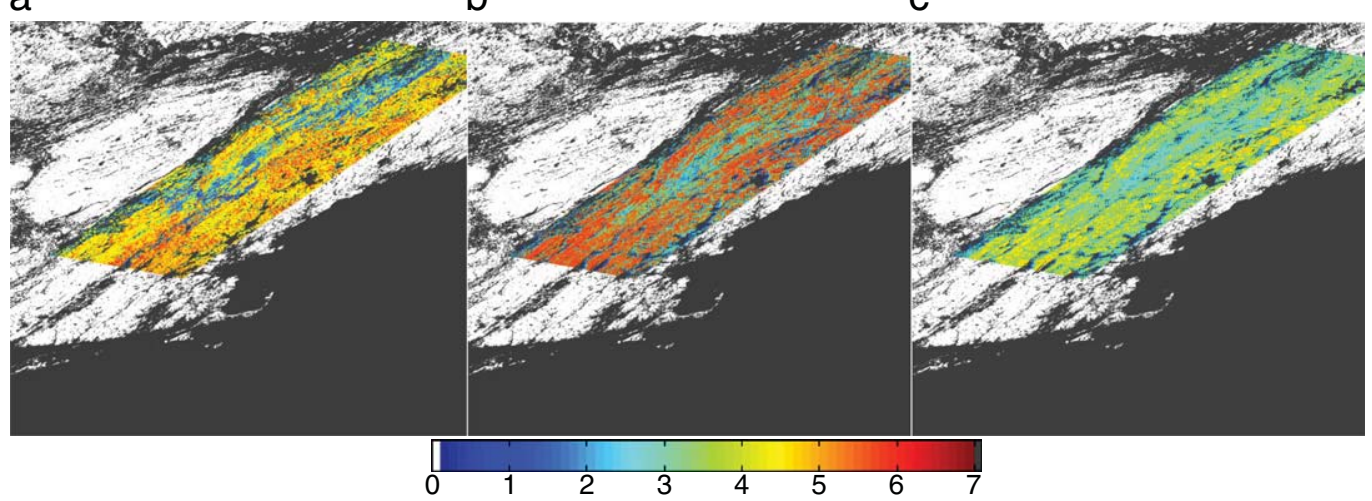

d

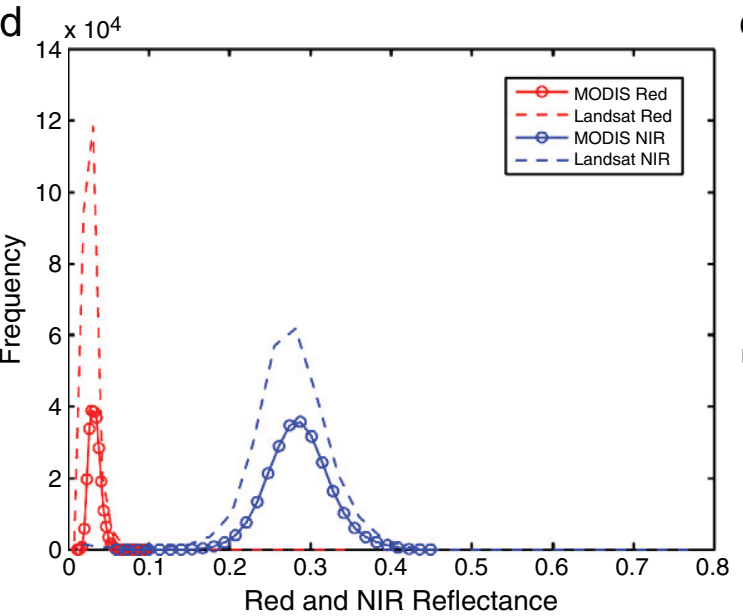

e

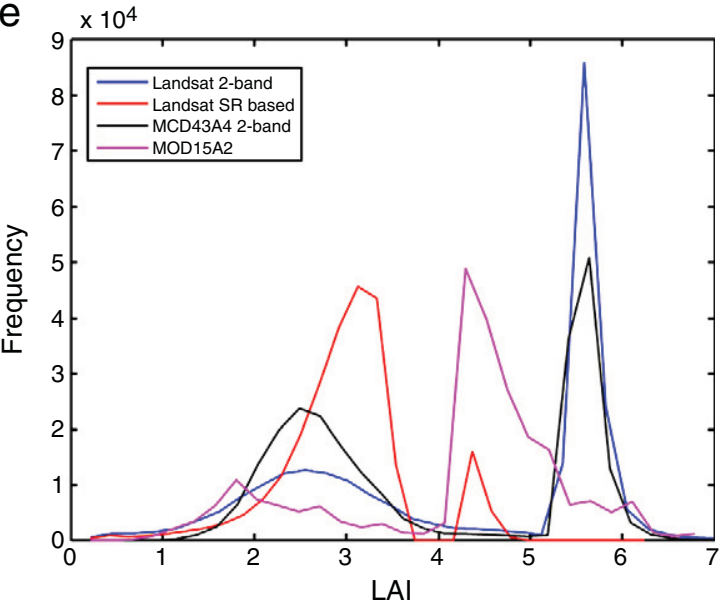

Fig. 12. (a) MOD15A2 LAI map for a homogeneous site representing deciduous broadleaf forests at Harvard forest, USA. The 500-m resampled Landsat scene with valid reflectances masks the region of interest and is superimposed in the MODIS tile h12v04. The backdrop represents the masked MODIS tile with white color denoting deciduous broadleaf pixels as classified by the MODIS land cover map and the gray pixels denoting all other values. (b) Same as (a) but showing Landsat-derived LAI with a 2-band inversion. (c) Same as (a) but showing Landsat-derived LAI by using the SR-LAI empirical rule. (d) Frequency distribution of RED and NIR values for MODIS (MCD43A4 product) and Landsat. (e) Frequency distribution of LAI from Landsat (2-band inversion and SR based), MCD43A4 (2-band inversion) and MOD15A2.

A list of all the datasets used in this study is given in Table 3.

\subsection{LAI retrieval from MODIS and Landsat surface reflectance at 500-m}

We implement the LAI algorithm described in Section 2.2 to retrieve LAI from the MCD43A4 and the aggregated Landsat 500-m RED and NIR spectral reflectances (cf. Section 3.3.1) for the scenes and tiles described in Table 1 . The LAI retrieval algorithm ingests the Landsat RED and NIR bands and the corresponding land cover from the MCD12Q1 product. The LUT simulation is performed using the prescribed values of single scattering albedos of the RED and NIR spectral bands and corresponding relative uncertainties from the MOD15A2 operational LUT entries. Consistent with the MODIS methodology (Knyazikhin et al., 1998, Yang et al., 2006), we implement a 2-band inversion to produce the $500-\mathrm{m}$ Landsat LAI. The same algorithm is executed for the MCD43A4 product to derive LAI from the NBAR reflectances.

Besides implementing a 2-band inversion algorithm, we also compute a Landsat LAI based on biome-specific empirical Simple Ratio (SR)-LAI relationships. The biome-specific SR-LAI relationships are obtained directly from the MOD15A2 LUT entries. The SR is calculated as the ratio of modeled NIR to RED spectral reflectances. The modeled values of SR and the corresponding LAIs from the LUT are pooled for each biome to develop a biome-specific functional relationship (e.g. Myneni et al., 2002; Shabanov et al., 2005).

\subsection{LAI algorithm implementation at 30-m}

Following the approach described in Section 2.2, we implement both a 2-band and 3-band (RED, NIR and SWIR) inversion algorithm to generate a 30-m LAI from the atmospherically corrected Landsat data for California (Section 3.3). The availability of the 30-m short-wave infrared band adds more information content in localizing a pixel during the retrieval process, however the utility of this band in retrieving LAI over large extents is yet to be investigated.

The remapped NLCD eight-biome classification map (Section 3.2) is used to assign the input reflectance pixels to the biome-specific LUT-based inversion. Both the 3-band and the 2-band inversion algorithm minimize the merit function (Eq. 10) for an input Landsat pixel given the RED, NIR and SWIR surface reflectances from the Landsat bands and the corresponding biome-specific LUT entries for BRF as a function of LAI, soil and sun/view geometry. There can be situations where the inversion fails to localize a solution set (for reflectances that do not fall in the simulated LUT canopy realizations) and in such cases, the SR-LAI based empirical rule (Section 3.4) derived from the LUT entries is applied to retrieve the LAI. In addition, a threshold value for RED reflectances is applied to each biome based on the results from Section 4.1 to help identify pixels that are not representative of the specific canopy architecture for which the LUT is formulated (cf. column 5 in Table 4). 
a

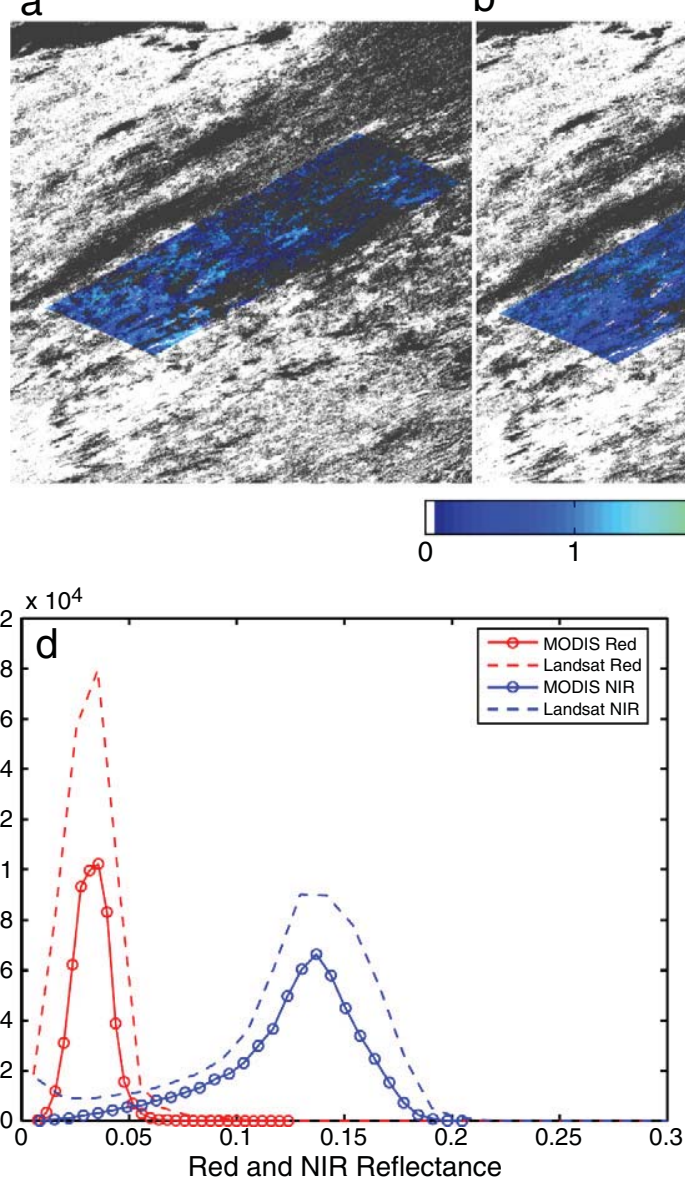

b
C
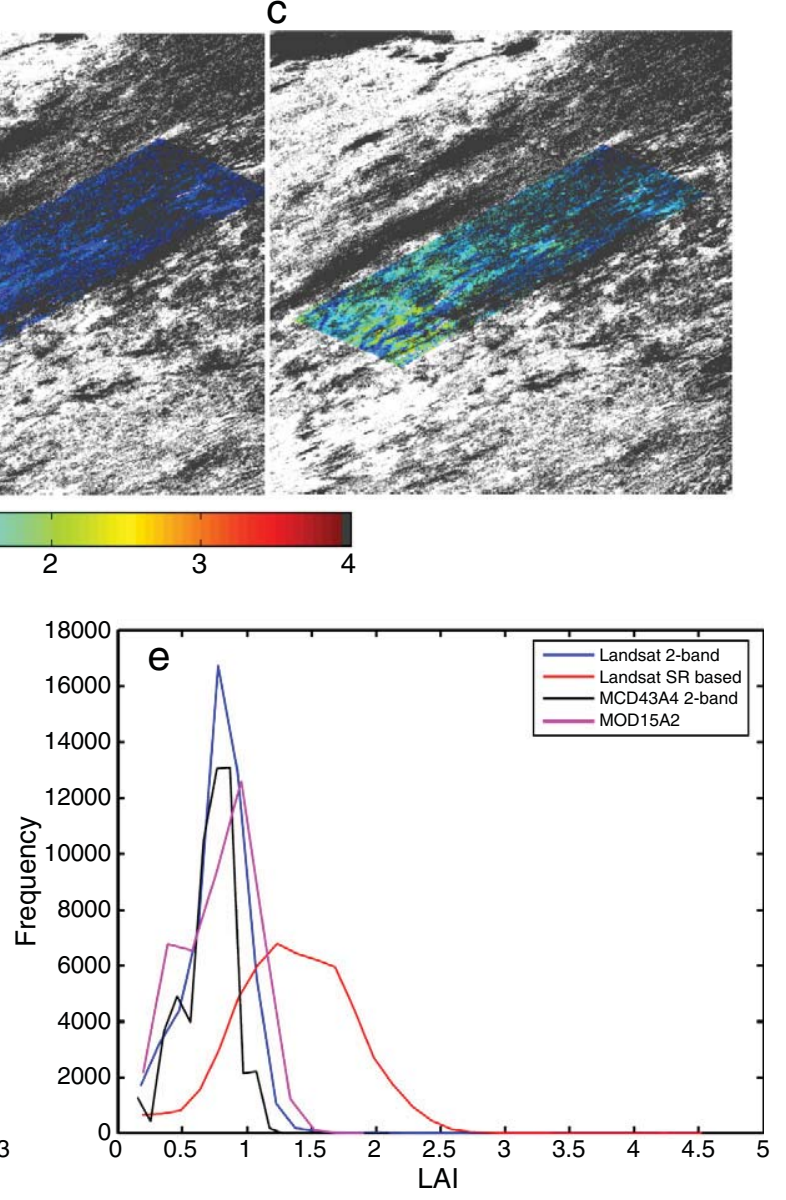

Fig. 13. (a) MOD15A2 LAI map for a homogeneous site representing evergreen needleleaf forests at a site in BOREAS, Canada. The 500-m resampled Landsat scene with valid reflectances masks the region of interest and is superimposed in the MODIS tile h12v03. The backdrop represents the masked MODIS tile with white color denoting evergreen needleleaf pixels as classified by the MODIS land cover map and the gray pixels denoting all other values. (b) Same as (a) but showing Landsat-derived LAI with a 2-band inversion. (c) Same as (a) but showing Landsat-derived LAI by using the SR-LAI empirical rule. (d) Frequency distribution of RED and NIR values for MODIS (MCD43A4 product) and Landsat. (e) Frequency distribution of LAI from Landsat (2-band inversion and SR based), MCD43A4 (2-band inversion) and MOD15A2.

\section{Results and discussion}

\subsection{Spectral signatures}

Although all vegetation types have relatively similar spectral properties (large absorption in the RED and large reflectance in NIR), different biomes have special characteristics depending on the canopy architecture. These characteristics can be discerned by comparing spectral signatures. Fig. 2 presents the reflectance behavior in the RED-NIR spectral plane at different levels of spatial aggregation (cf. Section 3.3.1), for the Landsat scenes in Table 1 that are representative of grasses, shrubs, deciduous broadleaf forest and deciduous needleleaf forest. The resampled land cover maps (Section 3.2) are used to sample reflectance pixels at each resolution. This allows a methodical inspection of reflectance characteristics and the purity of pixels as the reflectances are sampled from a finer resolution to a coarser one. Although the scenes are screened of clouds and atmospheric noise, some vegetated pixels at higher resolutions $(50-\mathrm{m}$ and $100-\mathrm{m}$ ) show unrealistic values of reflectances in the RED and NIR bands (e.g. 12\% of all pixels in Fig. 2(c) showing RED reflectances greater than 0.2) - an independent diagnosis categorizes these pixels as representative of bare soil, built-up areas, roads and/or nonvegetated surfaces that are misclassified by the NLCD map. Fig. 3(a) and (b) depict differences in spectral reflectances between Landsat and MODIS (Section 3.1) by incorporating the MODIS land cover map (30-m downsampled; Section 3.2) and the NLCD map over a homogenous region of broadleaf deciduous forests at Harvard forest (Landsat tile path/row: 13/30). The spectral reflectances of MODIS and Landsat as referenced by the NLCD map represent the purest $30-\mathrm{m}$ forest pixel, while the reflectances identified using a MODIS land cover shows a more mixed behavior. This example demonstrates that the characterization of a pure 30 -m reflectance pixel, representative of a specific vegetation type, requires a high-resolution land cover map at or near the Landsat scale of observation to reduce errors in retrieved 30-m LAIs because of increased probability of biome misclassifications as the spatial resolution decreases.

\subsection{Comparison of Landsat reflectances with resampled MODIS data}

We performed a comparative analysis of reflectance behavior with the 30-m resampled MCD43A4 product (cf. Section 3.1) and Landsat for the scenes presented in Table 1. Figs. 4-6 present an analysis of spectral behavior and the Normalized Difference Vegetation Index (NDVI) over regions dominated by grasses, broadleaf deciduous forests (BDF) and evergreen needleleaf forests (ENF). The NDVI shows similar spatial patterns between Landsat and MODIS with the former being higher than MODIS in a majority of the pixels (Figs. 4-6(a) and (b)). The NDVI difference map shows magnitudes between \pm 0.05 for the majority of the pixels, except for the needleleaf biome (Fig. 6(c)), where the differences lie mostly between 0.05 and 0.1 . The effect of the spatial resolution of observation is also evident in the spectral plots. The MODIS reflectances at $30-\mathrm{m}$ are a replication of $500-\mathrm{m}$ 

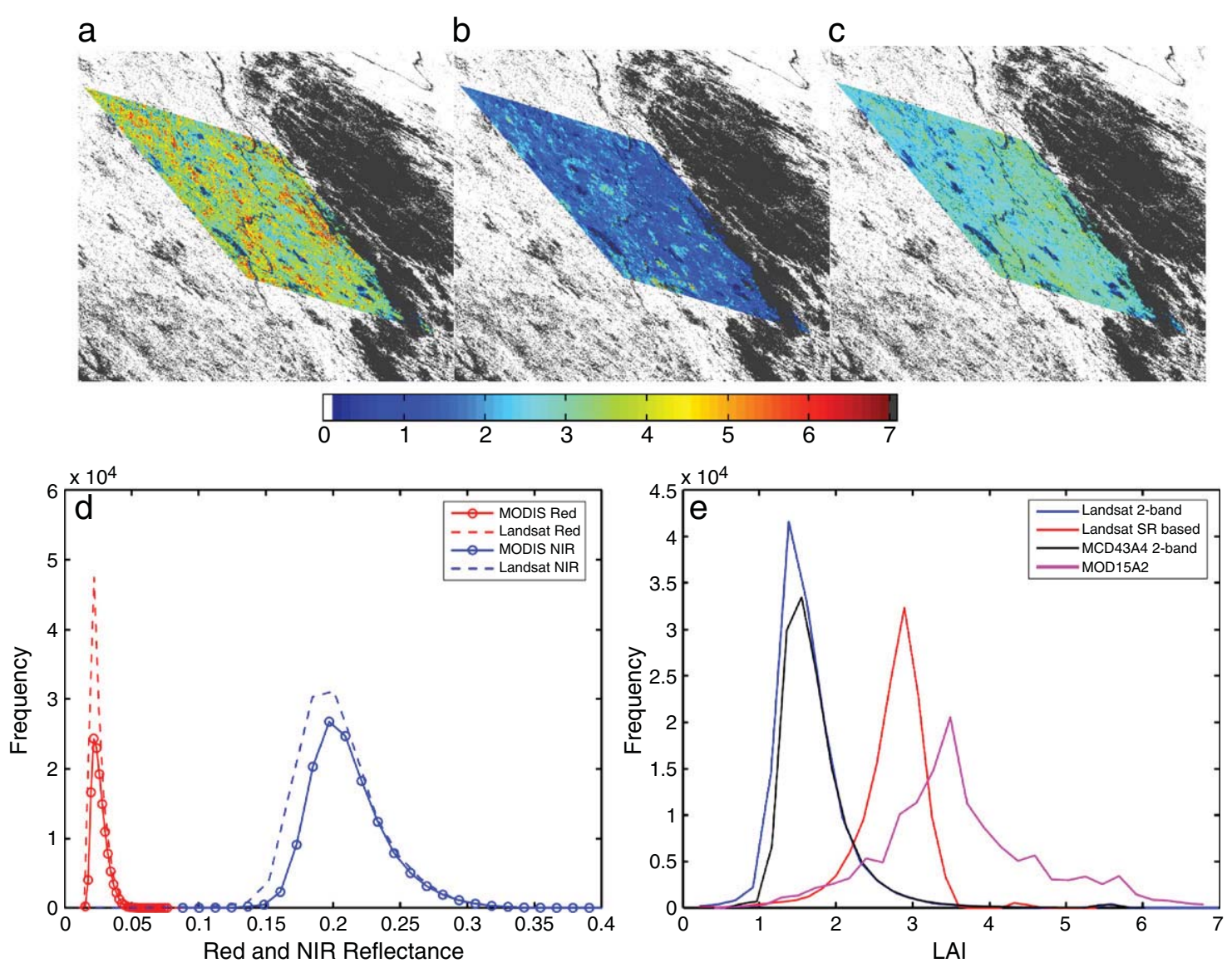

Fig. 14. (a) MOD15A2 LAI map for a homogeneous site representing deciduous needleleaf forests at the far north of Eastern Siberia. The 500-m resampled Landsat scene with valid reflectances masks the region of interest and is superimposed in the MODIS tile h23v03. The backdrop represents the masked MODIS tile with white color denoting deciduous needleleaf pixels as classified by the MODIS land cover map and the gray pixels denoting all other values. (b) Same as (a) but showing Landsat-derived LAI with a 2-band inversion. (c) Same as (a) but showing Landsat-derived LAI by using the SR-LAI empirical rule. (d) Frequency distribution of RED and NIR values for MODIS (MCD43A4 product) and Landsat. (e) Frequency distribution of LAI from Landsat (2-band inversion and SR based), MCD43A4 (2-band inversion) and MOD15A2.

reflectances and hence do not represent a true 30-m signal. The overlap region with Landsat (red colored pixels in Fig. 4(d)) identifies the maximum spectral density region of the biome type. It is evident that at $500-\mathrm{m}$, land cover heterogeneity is absent for the observed pixel and the sensor-measured BRF is an analytical convolution of the mixed pixel radiance with an average albedo representative of the pixel size. At a $30-\mathrm{m}$ Landsat pixel there is more heterogeneity and this is reflected in the higher dynamic range of RED and NIR values (e.g. Fig. 5(d)). For a 30-m pixel classified as forest, the sensormeasured BRF integrates the signal from pure observation components such as forest, bare soil, built-up land, understory and residual atmospheric noise.

Fig. 6(d) shows RED reflectance values between 0.15 and 0.5 near the soil line ( $\sim 13 \%$ of the total needleleaf forest pixels) that identify the signal attributable to bare soil and/or understory vegetation. Figs. 4(d) and 5(d) also show a similar effect with approximately $10-13 \%$ of the total pixels having RED reflectances greater than 0.2 for grasses and 0.1 for BDF. A specific striping pattern corresponding to low NIR values but with RED values between 0.2 and 0.6 (Fig. 5(d)) characterizes pixels that are recorded at the edge of the Landsat scene, and results from duplication issues related to SLC (Scan Line Corrector)-off data. The analysis outlined in this section is central to the physical principle of LAI retrieval. Pixels showing values of RED higher than permissible for a biome will correspond to solution sets of LAI not representative of forests - this renders it difficult to compare Landsat-derived LAIs to a coarse resolution LAI product like MODIS, where pure pixels are absent. Fig. 7 shows a polar plot of magnitude and direction for reflectance differences between Landsat and MODIS (RED and NIR) in the case of BDF pixels from Fig. 5. The right lower and upper quadrants in the polar plot show a majority of pixels ( $24 \%$ of all pixels) with difference magnitudes greater than zero and angles between $\pm 45^{\circ}$. This suggests that for Landsat pixels where the difference angular vector lies below $45^{\circ}$, coordinates of reflectance pairs are localized in a lower LAI isoline relative to MODIS (when the simulated LUT is same for both cases). Hence, LAI retrieved for all the 30-m pixels will be lower than MODIS LAI.

\subsection{Comparison of aggregated Landsat reflectances and LAI with MODIS}

Figs. 8-14 compare the spectral reflectances (Sections 3.1and3.3.1) and retrieved LAI (Sections 3.1and3.4) from MODIS and Landsat for a suite of biome types (Table 1 ) at the 500 -m spatial resolution. The spatial patterns and value distributions of Landsat-derived 2-band LAI, MCD43A4 2-band LAI and MOD15A2 LAI are comparable for biomes representing grasses, broadleaf crops, savannas, and ENF (Figs. 8-10 and 12). The differences among grasses, crops, savannas, and ENF are seen in the peak and tail of the LAI histograms. The frequency distribution of RED and NIR spectral bands from MODIS and Landsat are identical in most of the biomes with the exception of a slight overestimation in the NIR band of MODIS. Differences in peak frequency in the LAI histograms (inversion algorithm) are within 0.2 absolute units of LAI over grasses, crops, and ENF and within 0.5 absolute units for savannas. The empirical SR-based LAI is also presented in the analysis. The empirically derived LAI distribution function is similar to the inversion results for the herbaceous biomes, but shows mismatches for the EBF, ENF and DNF biomes. Forest 


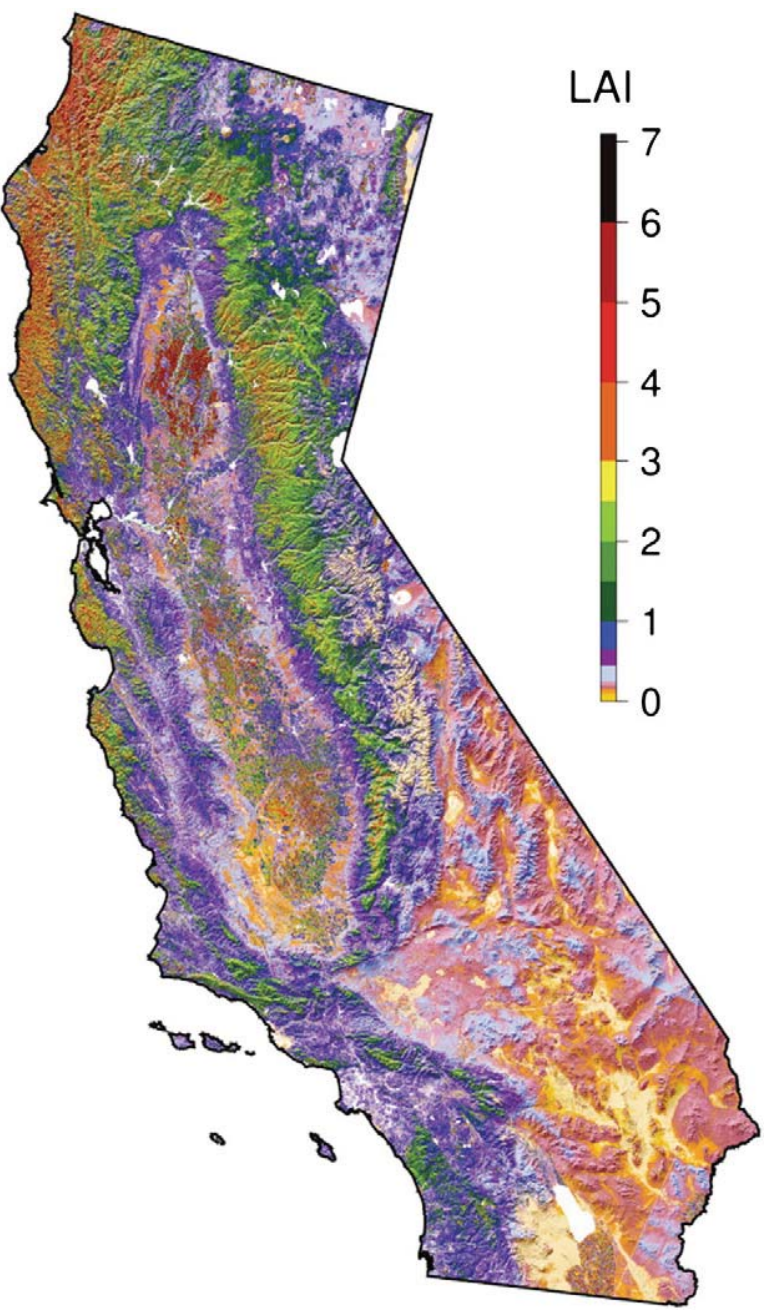

Fig. 15. A 30-m Landsat LAI map for California using a 2-band inversion algorithm. The LAI layer is draped over a 1-km shaded relief map to show topographical effects. 45 GLS 2005 Landsat scenes, representing the state of California, were processed using the LEDAPS framework to create surface reflectances as input to the LAI algorithm. The NLCD $200130-\mathrm{m}$ zonal land cover product was utilized as the ancillary biomeclassification map.

classes belonging to EBF, DNF and DBF show divergent behavior in the LAI profiles and have distributions distinct from the other biomes. The differences in peak frequency of LAI profiles (Landsat 2-band and MOD15A2) in the EBF are within 0.6 absolute units of LAI (Fig. 11(d)) and within 2 absolute units for DNF (Fig. 14(d)). In densely vegetated areas, such as in a majority of EBF pixels, MODIS/ Landsat surface reflectances become insensitive to incremental changes in leaf area - an issue known as saturation, which causes inconsistencies between MODIS and Landsat surface reflectances. Since LAI is retrieved from a small set of spectral values, the accuracy of these retrievals is lower. As is evident from Fig. 11(c), the NIR values for MODIS are higher compared to Landsat and the RED values for MODIS are lower, leading to a situation where the probability of a 2-band retrieval under saturation is higher in MODIS relative to Landsat. This results in retrieval inconsistencies and comparison of Landsat LAI retrievals to MODIS LAI for EBF is not warranted to the same degree as the other biomes (Knyazikhin et al., 1998; Shabanov et al., 2005). The DBF shows a bi-modal distribution with peaks centered at lower LAI values from 2 to 3 and in higher LAI region from 4 to 6 (Fig. 12(d)). The difference is within 0.6 LAI units in the lower LAI region while the same is accentuated in the higher LAIs with 1.3 absolute units of LAI. The Landsat-derived LAI for DBF is close to field measurements at Harvard forest that show a peak LAI value of 5.5 during the growing season (Table A4 in Ganguly et al., 2008b). The analysis from this section provides a robust platform for determining the consistency of Landsat-derived surface reflectances as compared to MODIS and highlights the effect associated with aggregating the $30-\mathrm{m}$ reflectances to a $500-\mathrm{m}$ spatial grid. The aggregation of the Landsat reflectances diminishes most of the pixel heterogeneity effects and results in a perfect overlap with the MODIS NBAR reflectances. The similarity between the three LAI retrievals (2-band inversion from Landsat and MODIS) also provides confidence in implementing the LAI algorithm at the Landsat $30-\mathrm{m}$ spatial resolution.

\subsection{LAI at 30-m: a case study over California}

The robustness of the resolution-dependent LUT retrievals of LAIs can only be verified with rigorous validation efforts at a range of observation scales, however, this is outside the scope of the present manuscript. Nonetheless, implementation of the LAI algorithm at a $30-\mathrm{m}$ resolution is physically justified with the specific conditions outlined in Section 3.5. First, the uncertainties in the input land cover are reduced by utilizing a high-resolution 30-m NLCD biome map, and hence the probability of selecting the incorrect LUTs due to errors in misclassification is minimized during the retrieval process. Second, the precision of the surface reflectance product depends on the extent to which atmospheric correction successfully removes the impact of clouds and aerosols on the measurements. While the LAI algorithm is designed to account for uncertainties in the surface reflectance product, the algorithm cannot retrieve LAI values with more precision than its inputs. The precision in the surface reflectance values from the LEDAPS atmospheric correction algorithm can only be evaluated with data from invariant targets, but this is outside the scope of the present discussion. Hence, the assumption is made that the quality of the output surface reflectance numbers is favorable enough for retrieving LAI within acceptable ranges of uncertainty. Finally, the mismatch between algorithm simulated reflectances and measured Landsat reflectances is minimized by tuning the biomespecific single scattering albedos, which results in a more accurate LAI retrieval by finding acceptable solution sets in a majority of pixels during the inversion process. The algorithm fails to localize a solution set in the band inversion process if there is a significant disparity between the simulated values and its measured counterpart.

Fig. 15 shows the full mosaic of Landsat-derived 30-m LAI for California from a 2-band inversion. The LAI is draped over a 1-km shaded relief map to show variations in the topography. A detailed quality

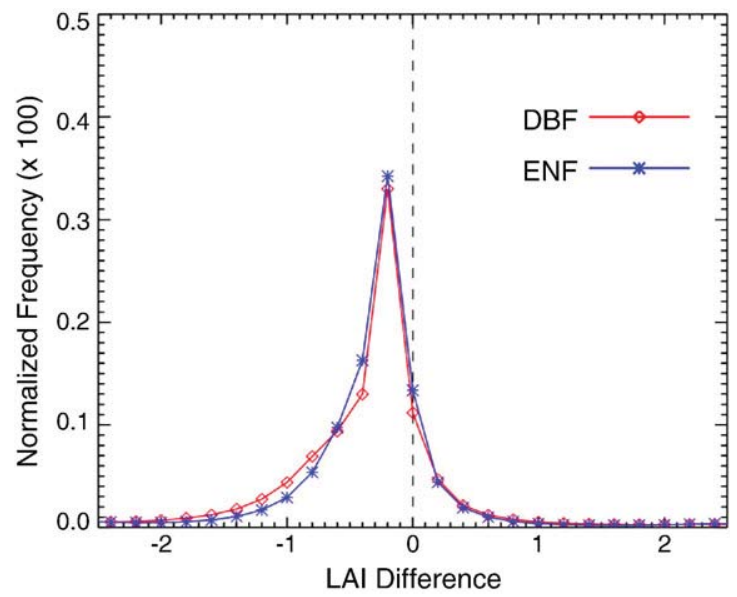

Fig. 16. LAI difference between a 3-band inversion and 2-band inversion for pixels classified as DBF and ENF for California. The NLCD 2001 map is used to classify the forest pixels. The frequency of LAI difference within a forest class is normalized to the total available forest pixels of the same class. 

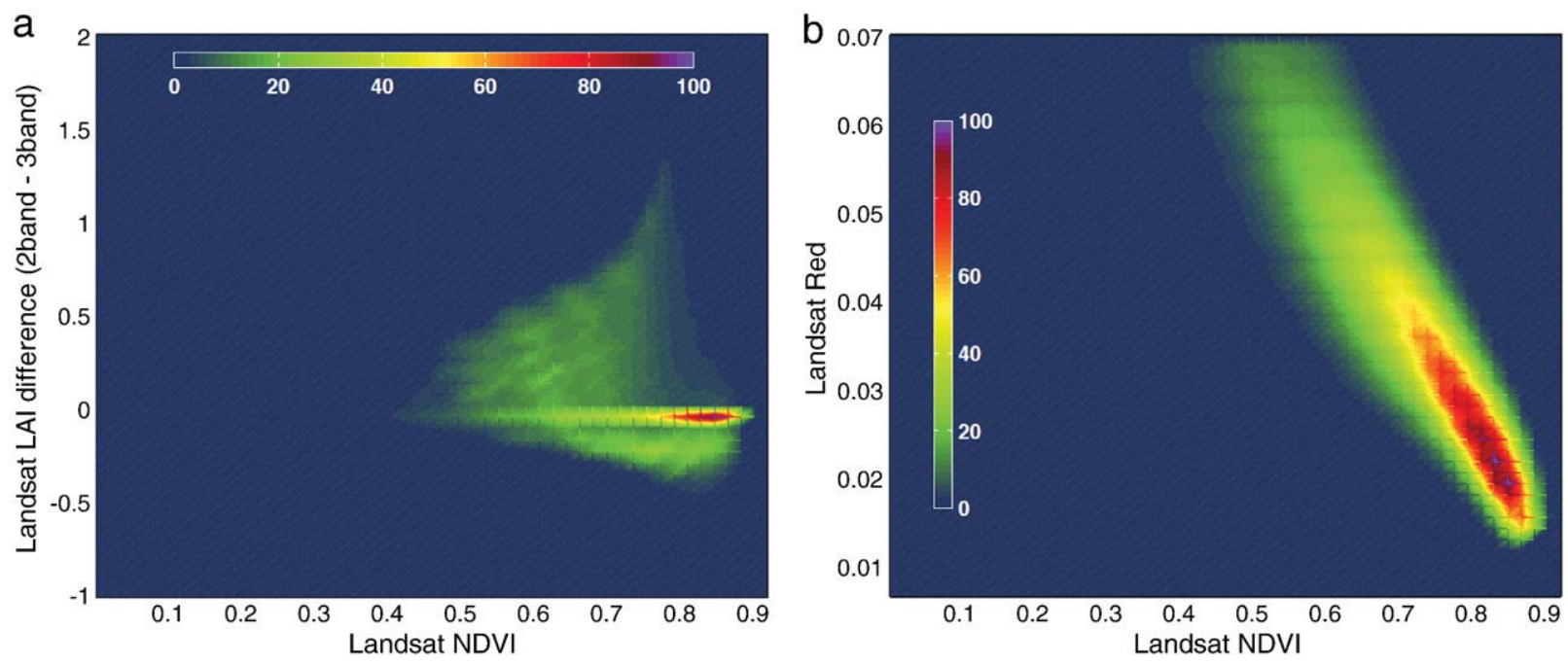

Fig. 17. (a) Density scatter plot between LAI difference (2-band inversion minus 3-band inversion) and Landsat-derived NDVI for pixels classified as needleleaf forests for a Landsat scene (path/row: 44/33) in the northwest California. The NLCD 2001 map is used to classify the forest pixels. The density number of the LAI difference within each NDVI bin is normalized to the range of density variation (max-min) in the LAI difference values. (b) Same as (a) but showing the scatter plot between Landsat RED reflectances and Landsat NDVI.

control layer, along with the LAI dispersion, is also generated during the retrieval process in order to tag pixels with the highest quality LAI values. Specifications of the quality layer can be further improved depending on user requirements and other guidelines needed for an operational product.

The implementation of a 3-band (inclusion of SWIR) inversion was also performed to evaluate the efficacy of the LAI retrieval algorithm as compared to a 2-band only inversion. Several recent studies from the boreal zone suggest that a pronounced understory effect could be minimized by the inclusion of the SWIR band (Brown et al., 2000; Stenberg et al., 2004). Fang and Liang (2003) also demonstrated the usefulness of using the SWIR band for estimating LAI using a Neural Network Model from ETM + surface reflectances. Overall, for California, the 3-band and the 2-band LAI products show minor differences for a majority of herbaceous biomes, while differences can be deemed significant in forest biomes with open canopies and in regions where topography effects such as canopy and hill shading are prevalent. The 3-band inversion yields lower LAI values than the 2-band inversion for the DBF and ENF forest categories in California (Fig. 16). This may be due to the crown-closure in this region being below a certain threshold value, causing the abundant understory to increase the LAI value in a 2-band inversion (Nemani et al., 1993; Rautiainen, 2005). Inclusion of the SWIR band decreases the LAI but the peak difference in LAI is centered on -0.2 units for $32 \%$ of the total forest pixels (Fig. 16). The negative difference value increases from 0.5 to 1 from $10 \%$ to $2 \%$ of the forested pixels.

To better understand the physical behavior of the 2-band versus 3-band inversion, we analyze the differences in the LAI estimates in the two inversion approaches for needleleaf forests pixels from a northeast region of California (Landsat scene path/row: 44/33). This region is characterized by a mixture of open and closed canopy needleleaf stands. Fig. 17(a) shows a percentage density plot between the LAI difference (2-band minus 3-band) and the Landsat-derived NDVI for these pixels. Pixels with an NDVI range from 0.5 to 0.75 show a 3-band LAI lower than the 2-band LAI with difference magnitudes that vary from 0 to 1 , signifying a pattern that is representative of an open canopy. The difference tapers to 0 for higher NDVI values (0.8-0.9) when the canopy approaches closure. The corresponding RED reflectances (Fig. 17(b)) also show an increase from 0.03 to 0.07 as one moves down the NDVI range from 0.75 to 0.5 , indicating the presence of open stands associated with understory vegetation and/or other highly reflective soil backgrounds. These results suggest that the $30-\mathrm{m}$ short-wave band assists in better localizing the reflectance of a conifer forest pixel and hence improves its LAI retrieval and, to a greater extent, minimizes the effects of moderately to high understory reflectance in the RED and NIR bands.

The inclusion of the SWIR band did not substantially improve the inverted LAI estimates over large regions as compared to a 2-band inversion, but its effect is seen in regions characterized by open canopy forests with understory effects. The complex interactions between topography, climate and soils produce a variety of canopy conditions at the Landsat resolution. In addition, there are monthly-to-seasonal changes in the soil moisture status due to changes in behavior in runoff conditions and precipitation regimes. While an operational 3-band based LAI retrieval can prove beneficial in such cases, the accuracy of the result needs to be established in future studies by validating field observed values of LAI and ground measured canopy-closure estimates.

\subsection{Expected accuracy of the LAI product}

Work presented here establishes a framework for retrieving LAI taking into account the native characteristics of the Landsat sensor in terms of its spatial resolution and spectral bandwidths. The formulation of the Landsat retrieval algorithm follows similar physical constraints present in the MODIS LAI algorithm and hence ensures consistency and complementarity (Ganguly et al., 2008a). However, determining the accuracy and precision of the LAI value depends on several aspects of the input data as well as the uncertainties associated with them.

The typical target accuracy required for LAI, in terms of RMSE, is approximately 0.5 units according to the Global Climate Observation System (GCOS, 2006). The MODIS stage 2 land validation efforts for the LAI product based on field measurements show that MODIS LAI is an overestimate by about $12 \%(\mathrm{RMSE}=0.66)$ of observed values when all biomes are taken into consideration (Yang et al., 2006; Ganguly et al., 2008b). Several field validation studies also suggest that the MODIS LAI gives reasonable estimates of LAI for most cover types and land use types (Hill et al., 2006; Huang et al., 2006; Kauwe De et al., 2011; Sea et al., 2011). At the very least, we believe the Landsat LAI estimates are just as accurate (cf.Section 4.3), though this needs further confirmation.

In Section 3.5, we provide the necessary filtering steps in order to classify a pure vegetated pixel that will result in an acceptable value of LAI using an inversion approach as compared to pixels with unrealistic RED/NIR spectral values. The quality flags for a pixel, describing the nature of the retrieval (inversion versus empirical) and the 
dispersion, both being associated with an LAI value, will guide the user in establishing the validity of the product. Our future activity will involve an accuracy assessment framework that will comprise initially of inter-comparing the derived LAI values from available Landsat scenes during validation campaigns from the existing network of sites like the BigFoot, AERONET, FLUXNET, EOS Land Validation Core Sites, and VALERI (see Garrigues et al., 2008; Morisette et al., 2006; Pisek \& Chen, 2007). This will be a part of a phased implementation and will build upon previous methodologies of validating coarse resolution satellite derived LAI maps (Ganguly et al., 2008b; Garrigues et al., 2008; Yang et al., 2006).

\section{Conclusions and future work}

This paper introduces a physically based approach for generating LAI at a 30-m Landsat scale. Our approach is based on the theory of canopy spectral invariants. The canopy spectral BRF is parameterized in terms of a compact set of parameters - spectrally varying soil reflectances, single-scattering albedo, spectrally invariant canopy interceptance, recollision probability and the directional escape probability. The approach ensures energy conservation and allows decoupling the structural and radiometric components of the BRF. According to this theory, the single scattering albedo accounts for the dependence of BRF on the sensor's spatial resolution and spectral bandwidth. We generate values of biome-specific single scattering albedos at the Landsat resolution by utilizing field observations of spectral albedo and further tuning with respect to remotely sensed spectral reflectances over a suite of biomes.

Analysis of spectral surface reflectances from Landsat with changes in spatial resolution shows that pixel heterogeneity diminishes at a coarser resolution and reflectances are comparable with the MODIS NBAR reflectance product. In order to achieve consistency with MODIS LAI, we implement the LAI algorithm with the aggregated 500-m Landsat reflectances for different herbaceous and forest biomes. Comparison of the 2-band inversion between Landsat at 500-m and the MOD15A2 LAI product shows satisfactory results for a majority of biome types. At a $30-\mathrm{m}$ resolution, the scalable inversion algorithm is further parameterized based on unrealistic values of RED that are in essence unrepresentative of the canopy realizations in our simulated model. The parameterized algorithm is implemented to generate a 30-m Landsat LAI map for California covering 45 GLS Landsat scenes. Inversion of the model is performed twice: first using two bands (RED and NIR), then using the SWIR band in addition to the RED and NIR bands. Overall, there are small differences in LAI (3-band versus 2-band) for a majority of herbaceous biomes. Over forest biomes, however, it appears that the presence of understory in open canopy forests and topographic effects can cause large differences in the LAI estimates from the two methods. Accurate evaluations of understory effects should be quantified with field LAI and canopy-closure measurements.

The algorithm presented in this study can potentially be applied globally to retrieve LAI from Landsat data through a physically based approach, although with some limitations. First, data measurement uncertainties from the different Landsat sensors can significantly impact the retrieval of a biophysical product. This requires better calibration and atmospheric correction algorithms, along with solar and view angle corrections for surface reflectance. Second, global retrievals of biophysical products utilize land cover classification maps, which set the bias for identifying the spatial heterogeneity of biome distribution. Classification inaccuracies are a critical source of error in the LAI retrieval process, especially for those regions undergoing dynamic land cover change (e.g. changes from herbaceous to woody biomes). The conterminous US has a 30-m NLCD land cover classification that certainly adds more information with respect to the coarser equivalents but a similar global product is not available. Finally, a global validation of Landsat-derived LAI with ground measurements is a complicated task because of issues with the aggregation of plot-level measurements to sensor resolution, limited temporal and spatial sampling of the ground data, field instrument calibrations, sampling errors, etc.

The limitations of the current retrieval algorithm include (1) accurately modeling the uncertainty of the input reflectances and incorporating the variability in model and input uncertainties with biome types; (2) incorporating a better understory reflectance characterization in simulating the "S problem;" and (3) validating the modeling of SWIR BRF through spectral invariant approximations with field measurements. Future research will continue along the following directions:

a) Implementation of the LAI algorithm for continental extents - this will involve characterizing the land cover types to evaluate the similarity in canopy architectural behavior between the same biome-type across different climatic regions;

b) Validation of 30-m LAI products with available field observations globally and establishment of the accuracies of a 3-band based inversion as compared to 2-band LAI estimates. The validation efforts will be an integral part of product assessment efforts which feed into algorithm refinement (cf. Section 4.4);

c) Utilization of the 30-m LAI product for high-resolution above ground biomass and NPP estimates;

d) Documenting changes in the growing season LAI globally from the 1980s to present utilizing the decadal GLS Landsat data and implementing phenological algorithms to accurately estimate growing season lengths from the Landsat time-series archive.

\section{Acknowledgments}

We acknowledge funding from Earth Science and Advanced Information Systems Technology programs at NASA. We would also like to extend our thanks to all the anonymous reviewers for their constructive comments, which did help us to improve and strengthen the paper. This research was performed using NASA Earth Exchange. NEX combines state-of-the-art supercomputing, Earth system modeling, remote sensing data from NASA and other agencies, and a scientific social networking platform to deliver a complete work environment in which users can explore and analyze large Earth science data sets, run modeling codes, collaborate on new or existing projects, and share results within and/or among communities.

\section{References}

Baret, F., Hagolle, O., Geiger, B., Bicheron, P., Miras, B., et al. (2007). LAI, fPAR and fCover CYCLOPES global products derived from VEGETATION Part 1: Principles of the algorithm. Remote Sensing of Environment, 110, 275-286.

Baret, F., Jacquemond, S., \& Hanocq, J. F. (1993). The soil line concept in remote sensing. Remote Sensing Reviews, 7, 65-82.

Brown, L., Chen, J. M., Leblanc, S. G., \& Cihlar, J. (2000). A shortwave infrared modification to the simple ratio for LAI retrieval in boreal forests an image and model analysis. Remote Sensing of Environment, 71(1), 16-25, doi:10.1016/S0034-4257(99)00035-8.

Brown, M., Pinzon, J. E., Didan, K., Morisette, J. T., \& Tucker, C. J. (2006). Evaluation of the consistency of long-term NDVI time series derived from AVHRR, SPOTvegetation, SeaWiFS, MODIS, and Landsat ETM + sensors. IEEE Transactions on Geoscience and Remote Sensing, 44(7), 1787-1793, doi:10.1109/TGRS.2005.860205.

Butson, C. R., \& Fernandes, R. A. (2004). A consistency analysis of surface reflectance and leaf area index retrieval from overlapping clear-sky Landsat ETM + imagery. Remote Sensing of Environment, 89, 369-380, doi:10.1016/j.rse.2003.10.017.

Chander, G., Huang, Chengquan, Yang, Limin, Homer, Collin, \& Larson, C. (2009) Developing consistent Landsat data sets for large area applications: The MRLC 2001 protocol. IEEE Geoscience and Remote Sensing Letters, 6(4), 777-781, doi: 10.1109/LGRS.2009.2025244.

Chander, G., Markham, B. L., \& Helder, D. L. (2009). Summary of current radiometric calibration coefficients for Landsat MSS, TM, ETM+, and EO-1 ALI sensors. Remote Sensing of Environment, 113(5), 893-903, doi:10.1016/j.rse.2009.01.007 Elsevier Inc.

Chen, J. M., Pavlic, G., Brown, L., Cihlar, J., Leblanc, S. G., White, H. P., et al. (2002). Derivation and validation of Canada-wide coarse-resolution leaf area index maps using high-resolution satellite imagery and ground measurements. Remote Sensing of Environment, 80(1), 165-184 Elsevier. Retrieved February 21, 2011, from. http:// cat.inist.fr/?aModele $=$ afficheN\&cpsidt $=13561848$ 
Demarty, J., Chevallier, F., Friend, A. D., Viovy, N., Piao, S., \& Ciais, P. (2007). Assimilation of global MODIS leaf area index retrievals within a terrestrial biosphere model. Geophysical Research Letters, 34(15), doi:10.1029/2007GL030014.

Fang, H., \& Liang, S. (2003). Retrieval of LAI from Landsat 7 ETM + data with a neural network method: Simulation and validation study. IEEE Transactions on Geoscience and Remote Sensing, 41(9), 2052-2062.

Fernandes, R., \& Butson, C. (2003). A Landsat TM/ETM + based accuracy assessment of leaf area index products for Canada derived from SPOT4/VGT data. Canadian Journal of Remote Sensing, 29(2), 241-258 Retrieved February 21, 2011, from. http://scholar.google.com/scholar?q=A+Landsat+TM\%2FETM\%2B + based + accuracy + assessment + of + leaf + area + index + products + for + Canada + derived +from +SPOT $4 \% 2 F V G T+$ data\&hl $=$ en\&btnG $=$ Search\&as $s d t=1 \% 2 C 5 \&$ as $\_$sdtp $=$on $\# 0$

Friedl, M. A., Sulla-Menashe, D., Tan, Bin, Schneider, A., Ramankutty, N., Sibley, A., et al. (2010). MODIS Collection 5 global land cover: Algorithm refinements and characterization of new datasets. Remote Sensing of Environment, 114(1), 168-182 Elsevier Inc.. 10.1016/j.rse.2009.08.016

Ganguly, S., Samanta, A., Schull, M., Shabanov, N., Milesi, C., Nemani, R., et al. (2008) Generating vegetation leaf area index Earth system data record from multiple sensors. Part 2: Implementation, analysis and validation. Remote Sensing of Environment, 112(12), 4318-4332, doi:10.1016/j.rse.2008.07.013.

Ganguly, S., Schull, M., Samanta, A., Shabanov, N., Milesi, C., Nemani, R., et al. (2008). Generating vegetation leaf area index earth system data record from multiple sensors. Part 1: Theory. Remote Sensing of Environment, 112(12), 4333-4343, doi: 10.1016/j.rse.2008.07.014 Elsevier Inc..

Garrigues, S., Lacaze, R., Baret, F., Morisette, J. T., Weiss, M., Nickeson, J. E., et al. (2008). Validation and intercomparison of global Leaf Area Index products from remote sensing data. Journal of Geophysical Research, 113, 1-20.

GCOS (2006). GCOS, Systematic observation requirements for satellite-based products for climate. WMO/TD No. 1338 September 2006 (2006) 103 pp. (available at. http:// www.wmo.ch/web/gcos/gcoshome.html

González-Sanpedro, M. C., Toan, T. L., Moreno, J., Kergoat, L., \& Rubio, E. (2008). Seasonal variations of Leaf Area Index of agricultural fields retrieved from Landsat data. Remote Sensing of Environment, 112, 810-824.

Gutman, B. G., Byrnes, R., Masek, J., Covington, S., Justice, C., Franks, S., et al. (2008). Towards monitoring land-cover and land-use changes at a global scale: The Global Land Survey 2005. Photogrammetric Engineering and Remote Sensing, 74, 6-10.

Hansen, M., Roy, D., Lindquist, E., Adusei, B., Justice, C., \& Altstatt, A. (2008). A method for integrating MODIS and Landsat data for systematic monitoring of forest cover and change in the Congo Basin. Remote Sensing of Environment, 112(5), 2495-2513, doi:10.1016/j.rse.2007.11.012.

Hill, M. J., Senaratha, U., Lee, A., Zeppel, M., Nightingale, J. M., Williams, R. D. J., et al. (2006). Assessment of the MODIS LAI product for Australian ecosystems. Remote Sensing of Environment, 101, 495-518.

Homer, C., Huang, C., Yang, L., Wylie, B., \& Coan, M. (2004). Development of a $2001 \mathrm{Na}-$ tional Land-Cover Database for the United States. Photogrammetric Engineering and Remote Sensing, 70(7), 829-840.

Huang, D., Knyazikhin, Y., Dickinson, R. E., Rautiainen, M., Stenberg, P., Disney, M., et al. (2007). Canopy spectral invariants for remote sensing and model applications. Remote Sensing of Environment, 106(1), 106-122.

Huang, D., Yang, W., Tan, B., Rautiainen, M., Zhang, P., Hu, J., et al. (2006). The importance of measurement error for deriving accurate reference leaf area index maps and validation of the MODIS LAI product. IEEE Transactions on Geoscience and Remote Sensing, 44, 1866-1871.

Jacquemond, S., Baret, F., \& Hanocq, J. F. (1992). Modeling spectral and bidirectional soil reflectance. Remote Sensing of Environment, 41, 123-132.

Kaufman, Y. J., Wald, A. E., Remer, L. A., et al. (1997). The MODIS 2.1-micron channel $\mathbb{E}$ correlation with visible reflectance for use in remote sensing of aerosol. IEEE Transactions on Geoscience and Remote Sensing, 35, 1286-1296.

Kauwe De, M. G., Disney, M. I., Quaife, T., Lewis, P., \& Williams, M. (2011). An assessment of the MODIS collection 5 leaf area index product for a region of mixed coniferous forest. Remote Sensing of Environment, 115, 767-780.

Knyazikhin, Y., \& Marshak, A. (2000). Mathematical aspects of BRDF modeling: Adjoint problem and Green's function. Remote Sensing Reviews, 18, 263-280.

Knyazikhin, Y., Marshak, A., \& Myneni, R. B. (2005). In A. Davis, \& A. Marshak (Eds.), Three-dimensional radiative transfer in vegetation canopies (pp. 617-651). New York: Springer.

Knyazikhin, Y., Martonchik, J. V., Myneni, R. B., Diner, D. J., \& Running, S. W. (1998) Synergistic algorithm for estimating vegetation canopy leaf area index and fraction of absorbed photosynthetically active radiation from MODIS and MISR data. Journal of Geophysical Research, 103(D24), 32257-32275, doi:10.1029/98JD02462.

Knyazikhin, Y., Schull, M. A., Xu, L., Myneni, R. B., \& Samanta, A. (2010). Canopy spectral invariants. Part 1: A new concept in remote sensing of vegetation. Journal of Quantitative Spectroscopy and Radiative Transfer, doi:10.1016/j.jqsrt.2010.06.014.

Kuusk, A., Lang, M., \& Nilson, T. (2004). Simulation of reflectance of ground vegetation in sub-boreal forests. Agricultural and Forest Meteorology, 126, 33-46

Kuusk, A., \& Nilson, T. (2000). A directional multispectral forest reflectance model. Remote Sensing of Environment, 72(2), 244-252, doi:10.1016/S0034-4257(99) 00111-X.

Lewis, P., \& Disney, M. (2007). Spectral invariants and scattering across multiple scales from within-leaf to canopy. Remote Sensing of Environment, 109(2), 196-206.

Masek, J. G., Vermote, E. F., Saleous, N. E., Wolfe, R., Hall, F. G., Huemmrich, K. F., et al. (2006). A Landsat surface reflectance dataset for North America, 1990-2000. IEEE Geoscience and Remote Sensing Letters, 3(1), 68-72, doi:10.1109/LGRS.2005.857030.

Morisette, J. T., Baret, F., Privette, J. L., Myneni, R. B., Nickeson, J. E., et al. (2006). Validation of global moderate-resolution LAI products: A framework proposed within the
CEOS land product validation subgroup. IEEE Transactions on Geoscience and Remote Sensing, 44(7), 1804-1817.

Myneni, R. B., Hoffman, S., Knyazikhin, Y., Privette, J. L., Glassy, J., Tian, Y., et al. (2002). Global products of vegetation leaf area and fraction absorbed PAR from year one of MODIS data. Remote Sensing of Environment, 83(1-2), 214-231.

Myneni, R. B., Keeling, C. D., Tucker, C. J., Asrar, G., \& Nemani, R. R. (1997). Increased plant growth in the northern high latitudes from 1981 to 1991. Nature, 386(6626), 698-702, doi:10.1038/386698a0.

Nemani, R., Pierce, L., Running, S., \& Band, L. (1993). Forest ecosystem processes at the watershed scale: Sensitivity to remotely-sensed Leaf Area Index estimates. International Journal of Remote Sensing, 14(13), 2519-2534, doi: $10.1080 / 01431169308904290$.

Peltoniemi, J. I., Kaasalainen, S., Näränen, J., Rautiainen, M., Stenberg, P., Smolander, H., et al. (2005). BRDF measurement of understory vegetation in pine forests: Dwarf shrubs, lichen and moss. Remote Sensing of Environment, 94(3), 343-354.

Pisek, J., \& Chen, J. M. (2007). Comparison and validation of MODIS and VEGETATION global LAI products over four BigFoot sites in North America. Remote Sensing of Environment, 109, 81-94.

Rautiainen, M. (2005). Retrieval of leaf area index for a coniferous forest by inverting a forest reflectance model. Remote Sensing of Environment, 99, 295-303.

Roman, M., Schaaf, C. B., Woodcock, C. E., et al. (2009). The MODIS (Collection V005) BRDF/albedo product: Assessment of spatial representativeness over forested landscapes. Remote Sensing of Environment, 113, 2476-2498.

Roy, D. P., Ju, J., Kline, K., Scaramuzza, P. L., Kovalskyy, V., Hansen, M., et al. (2010). Web-enabled Landsat Data (WELD): Landsat ETM + composited mosaics of the conterminous United States. Remote Sensing of Environment, 114(1), 35-49, doi: 10.1016/j.rse.2009.08.011 Elsevier Inc..

Schaaf, C. B., Gao, F., Strahler, A. H., Lucht, W., Li, X. W., Tsang, T., et al. (2002). First operational BRDF, albedo nadir reflectance products from MODIS. Remote Sensing of Environment, 83(1-2), 135-148.

Sea, W. B., Choler, P., Beringer, J., Weinmann, R. A., Hutley, L. B., \& Leuning, R. (2011). Documenting improvement in leaf area index estimates from MODIS using hemispherical photos for Australian savannas. Agricultural and Forest Meteorology, 151, 1453-1461.

Sellers, P. J., Randall, D. A., Collatz, G. J., Berry, J. A., Field, C. B., Dazlich, D. A., et al. (1996). A revised land surface parameterization (SiB2) for atmospheric GCMs. 1. Model formulation. Journal of Climate, 9(4), 676-705.

Shabanov, N. V., Huang, D., Yang, W., Tan, B., Knyazikhin, Y., et al. (2005). Analysis and optimization of the MODIS Leaf Area Index algorithm retrievals over broadleaf forests. IEEE Transactions on Geoscience and Remote Sensing, 43(8), 1855-1865.

Smolander, S., \& Stenberg, Pauline (2005). Simple parameterizations of the radiation budget of uniform broadleaved and coniferous canopies. Remote Sensing of Environment, 94(3), 355-363, doi:10.1016/j.rse.2004.10.010.

Spanner, M. A., Pierce, L. L., Peterson, D. L., \& Running, S. W. (1990). Remote sensing of temperate coniferous forest leaf area index: The influence of canopy closure, understory vegetation and background reflectance. International Journal of Remote Sensing, 11, 95-111

Stenberg, Pauline, Rautiainen, Miina, \& Manninen, T. (2004). Reduced simple ratio better than NDVI for estimating LAI in Finnish pine and spruce stands. Silva Fennica, $38,3-14$.

Tarnavsky, E., Garrigues, S., \& Brown, M. (2008). Multiscale geostatistical analysis of AVHRR, SPOT-VGT, and MODIS global NDVI products. Remote Sensing of Environment, 112(2), 535-549, doi:10.1016/j.rse.2007.05.008.

Tian, Y. (2004). Comparison of seasonal and spatial variations of leaf area index and fraction of absorbed photosynthetically active radiation from Moderate Resolution Imaging Spectroradiometer (MODIS) and Common Land Model. Journal of Geophysical Research, 109(D1), D01103, doi:10.1029/2003JD003777 American Geophysical Union.

Van leeuwen, W., Orr, B., Marsh, S., \& Herrmann, S. (2006). Multi-sensor NDVI data continuity: Uncertainties and implications for vegetation monitoring applications. Remote Sensing of Environment, 100(1), 67-81, doi:10.1016/j.rse.2005.10.002.

Wang, Y., Buermann, W., Stenberg, P., Smolander, H., Hame, T., Tian, Y., et al. (2003). A new parameterization of canopy spectral response to incident solar radiation: Case study with hyperspectral data from pine dominant forest. Remote Sensing of Environment 85(3), 304-315, doi:10.1016/S0034-4257(03)00009-9.

Wang, Y., Tian, Y., Zhang, Y., El-Saleous, N., Knyazikhin, Y., Vermote, E., et al. (2001). Investigation of product accuracy as a function of input and model uncertainties Case study with SeaWiFS and MODIS LAI/FPAR algorithm. Remote Sensing of Environment 78(3), 299-313, doi:10.1016/S0034-4257(01)00225-5.

Wang, Y. J., Woodcock, C. E., Buermann, W., Stenberg, P., Voipio, P., Smolander, H., et al. (2004). Evaluation of the MODIS LAI algorithm at a coniferous forest site in Finland. Remote Sensing of Environment, 91(1), 114-127, doi:10.1016/j.rsc.2004.02.007.

Woodcock, C. E., Allen, R., Anderson, M., Belward, A., Bindschadler, R., Cohen, W., et al. (2008). Free access to Landsat imagery. Science, 320(5874), 1011.

Wulder, M., Loubier, E., \& Richardson, D. (2002). Landsat-7 ETM + orthoimage coverage of Canada. Canadian Journal of Remote Sensing, 28(5), 667-671.

WWW1 (). NASA MODIS land report on LAI/FPAR. http://modis.gsfc.nasa.gov/MODIS/ LAND/REPORTS/myneni.1998.2.pdf

WWW2 (). LEDAPS surface reflectance product description. http://ledaps.nascom.nasa. gov/docs/pdf/SR_productdescript_dec06.pdf

Yang, W., Tan, B., Huang, D., Rautiainen, M., Shabanov, N. V., Wang, Y., et al. (2006) MODIS leaf area index products: From validation to algorithm improvement. IEEE Transactions on Geoscience and Remote Sensing, 44(7), 1885-1898, doi: 10.1109/TGRS.2006.871215. 